NOTICE: This is the peer reviewed version of the following article: Marcote, D. C., Varela, I., Fernández-Casado, J., Mascareñas, J.L., López*, F. (2019), Gold(I)-catalyzed enantioselective annulations between allenes and alkene-tethered oxime ethers: A straight entry to highly substituted piperidines and aza-bridged medium-sized carbocycles. J. Am. Chem. Soc., 140, 16821-16833 [doi: 10.1021/jacs.8b10388]. This article may be used for non-commercial purposes in accordance with ACS Terms and Conditions for self-archiving.

\title{
Gold(I)-catalyzed enantioselective annulations between allenes and alkene-tethered oxime ethers: A straight entry to highly substituted pi- peridines and aza-bridged medium-sized carbocycles
}

\author{
David C. Marcote, ${ }^{\dagger,}$ Iván Varela, ${ }^{\dagger},+$ Jaime Fernández-Casado, ${ }^{\dagger}$ José L. Mascareñas, ${ }^{*},{ }^{\dagger}$ Fernando Ló- \\ pez ${ }^{*, \dagger, \#}$
}

${ }^{\dagger}$ Centro Singular de Investigación en Química Biolóxica e Materiais Moleculares (CiQUS) and Departamento de Química Orgánica. Universidad de Santiago de Compostela, 15782, Santiago de Compostela, Spain

\# Instituto de Química Orgánica General CSIC, Juan de la Cierva 3, 28006, Madrid, Spain

\section{Supporting Information Placeholders}

\begin{abstract}
Piperidine scaffolds are present in a wide range of bioactive natural products, and are therefore considered as highly valuable, privileged synthetic targets. In this manuscript, we describe a gold-catalyzed annulation strategy that allows a straightforward assembly of piperidines and piperidine-containing azabridged products from readily available alkene-tethered oxime ethers (or esters) and $\mathrm{N}$-allenamides. Importantly, we demonstrate the advantages of using oxime derivatives over imines, something pertinent to the whole area of gold catalysis, and provide relevant mechanistic experiments that shed light into the factors affecting the annulation processes. Moreover, we also describe preliminary experiments demonstrating the viability of enantioselective versions of the above reactions.
\end{abstract}

\section{INTRODUCTION}

Nitrogen-based heterocycles form the basic structural framework of many bioactive natural products, and are present in more than $50 \%$ of marketed drugs. ${ }^{1}$ Especially abundant among these heterocycles are those featuring a piperidine skeleton, a privileged structure that forms the core of many alkaloids exhibiting potent biological activities, including antitumoral, antihypertensive, antibiotic or anesthetic profiles, among others (Figure 1). ${ }^{2}$ Although numerous stereoselective approaches for assembling piperidines have been developed, most of them require several steps and/or the use of elaborated precursors; ${ }^{3}$ and in many cases they do not comply with the principles of atom-economical synthesis. ${ }^{4}$ Moreover, the number of enantioselective approaches that allow a one-step access to these scaffolds is rather limited. ${ }^{5}$ These drawbacks are even more pronounced in the case of piperidines containing highly substituted carbon stereocenters adjacent to their nitrogen atom. ${ }^{6}$

The piperidine scaffold is also embedded in the skeleton of many polycyclic natural products exhibiting complex structures. ${ }^{7}$ Especially relevant because of their biological and medical significance are those which feature tropane-like aza-bridged skeletons (Figure 1). Indeed, there are hundreds of alkaloids exhibiting azabicyclo[3.2.1] octane frameworks, with several of them being used in the clinic. ${ }^{8}$ The prominence of these aza-bridged bicyclic products has stimulated important synthetic efforts in the area, however most of the approaches so far developed rely on stoichiometric rather than catalytic processes, and very few involve enantioselective catalysis. ${ }^{9}$ Moreover, most of these methods are restricted to the building of aza-bridged products with a seven-membered carbocycle, so catalytic entries to challenging eight- and nine-membered counterparts, are very scarce. ${ }^{10}$ In this context, the development of catalytic, versatile and enantioselective approaches to $\alpha$-substituted piperidines and aza-bridged piperidine-containing products is of upmost interest.

Figure 1. Some aza-heterocycles containing piperidine scaffolds, some of them with highly substituted $\alpha$-carbons<smiles>CC=C=C[C@H]1CCC(O)[C@@H](C)N1C</smiles>
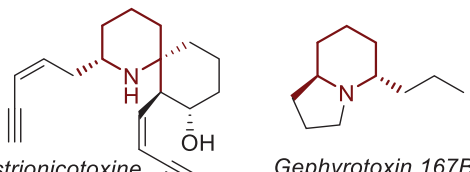

Valachine

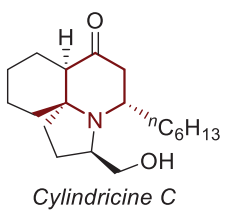

Gephyrotoxin 167B
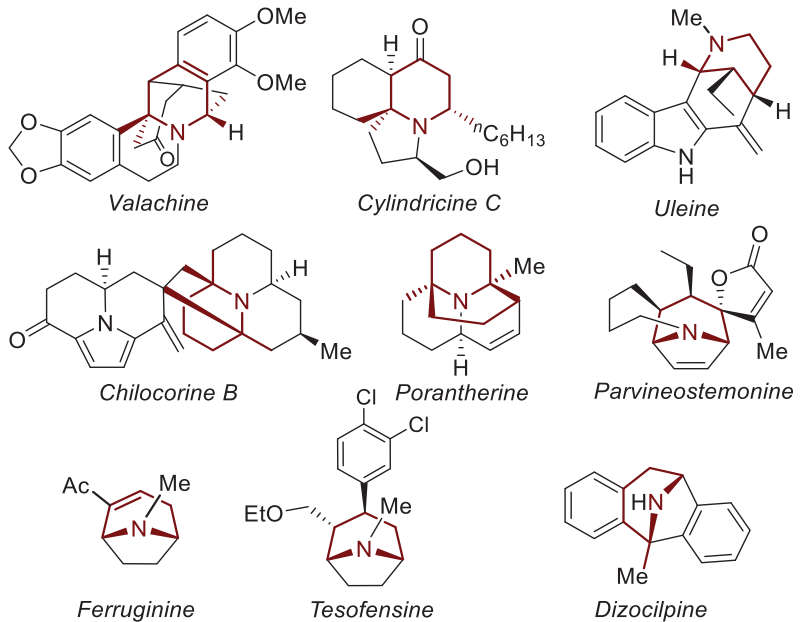

Porantherine

Parvineostemonine

Ferruginine Tesofensine

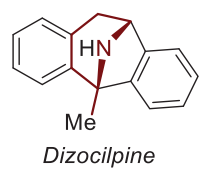

As part of our ongoing work in gold catalysis, ${ }^{11}$ we have recently reported a gold-catalyzed annulation between allenamides and alkene-tethered carbonyl derivatives that allows a straightforward assembly of oxa-bridged medium-sized carbocycles. ${ }^{2}$ Additionally, we have developed a fully intermolecular annulation between allenamides, alkenes and carbonyl derivatives, which provides highly substituted tetrahydropyran systems in high yield and with moderate to good diastereo- and enantioselectivities (Scheme 1). ${ }^{13}$ These 
annulations have been proposed to proceed by an initial activation of the allene moiety by the gold(I) complex, which likely generates a zwitterionic intermediate of type $\mathbf{I} .{ }^{14}$ This species undergoes the addition of the alkene to its $\gamma$-position to provide a carbocationic intermediate II, in which an electrostatic interaction between the gold(I) atom and the carbocation has been proposed to account for the observed stereospecificity. ${ }^{13 a}$ Then, an inter- or intramolecular interception of this carbocation by the carbonyl moiety generates an oxonium (III), which undergoes a Prins-like cyclization to deliver the observed oxacycle.

Scheme 1. Previous Au-catalyzed formal $[2+2+2] \mathbf{C y}-$ cloadditions Towards $O x a$-heterocycles ${ }^{12,13}$<smiles>[R][Z](C([R])=[R])C(=O)NC=C</smiles>

$$
\underset{[2+2+2]}{\stackrel{[\mathrm{Au}] \text { (cat) }}{\longrightarrow}}
$$

$[N]=$ sulfonyl or carbonyl amide

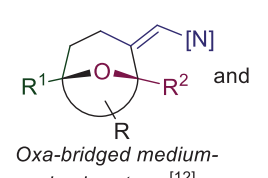
Oxa-bridged medium-
sized systems $^{[12]}$

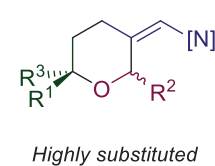

Highly substituted tetrahydropyrans ${ }^{[13]}$
Mechanistic scenario for the $[2+2+2]$ process with carbonyl partners:

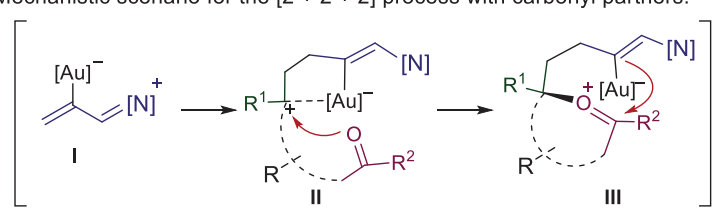

With this conceptual framework at hand, we questioned whether it would be possible to extend this methodology to imine instead of carbonyl partners, and therefore lever a direct, atom-economical entry to densely substituted piperidine-containing scaffolds, including aza-bridged medium sized carbocycles (Scheme 2, products $\mathbf{A}$ and $\mathbf{B}$ ).

Although this extrapolation could appear trivial, finding a gold catalyst compatible with imine partners, and capable of triggering the desired annulation with allenes to produce azacyclic products, is far from obvious. Indeed, despite extraordinary advances in homogeneous gold catalysis during the last two decades, most annulation processes are still limited to the generation of carbocycles and oxygen-based heterocycles; ${ }^{15}$ with progress on gold-catalyzed annulations using nitrogenated partners clearly lagging behind. The reasons behind this disparity might be rooted in the intrinsic properties of gold(I) complexes since, despite their acute carbophilicity, they also show affinity for soft Lewis bases such as amines and imines, which therefore interfere with the activity of the gold(I) reagents. ${ }^{16-}$ ${ }^{18}$ In fact, the use of gold(I) catalysis in intermolecular reactions involving tertiary amines other than anilines is very scarce, and limited to very particular cases. ${ }^{19}$ Moreover, although several aza-reagents bearing less basic nitrogens ( $\mathrm{sp}$ - and $\mathrm{sp}^{2}$-nitrogens) can participate in gold(I) catalysis (e.g., nitriles, azides, pyridines or isoxazoles), intermolecular examples with simple imines are not abundant, usually require heating, and are typically limited to less basic aromatic or conjugated imines. ${ }^{20}$

In this context, discovering imine partners compatible with the carbophilic gold catalysts, but nucleophilic enough to intercept carbocationic intermediates of type $\mathbf{I V}$, is critical for succeeding in the desired annulations (Scheme 2). Also importantly, the iminium species $\mathbf{V}$ should be electrophilic enough to undergo the aza-Prinslike cyclization that would eventually deliver the product. ${ }^{21}$ Conversely, if the carbophilicity of the catalyst and the imine basicity are not properly matched, side products resulting from allenamide dimerizations and polymerizations, as well as bimolecular alkeneallenamide $[2+2]$ cycloadditions and hydrofunctionalizations could predominate (Scheme 2, products $\mathbf{C}-\mathbf{E}$ ). ${ }^{22}$ Additionally, the desired piperidine products (A and B) might also hamper the catalytic activity by coordinating the gold(I) complex. ${ }^{18}$
Herein, we demonstrate that these challenges can be efficiently approached by using oximes instead of imines as reactions partners. Specifically, we report a gold-catalyzed formal $[2+2+2]$ cycloaddition between $\mathrm{N}$-allenamides and $\mathrm{C}$ - or $\mathrm{O}$-tethered alkenyl oxime ethers that allows a direct, catalytic and efficient entry to highly substituted piperidine-based heterocyclic systems, as well as to synthetically appealing aza-bridged medium-sized carbocycles. Moreover, by performing the reaction with chiral phosphoramiditegold complexes, the products can be obtained in good to excellent enantiomeric ratios. Finally, we also detail relevant mechanistic experiments that shed light on the enantio- and turnover-determining steps of these processes, as well as on the reasons beyond the superior performance of oximes versus imines.

Scheme 2. Envisioned Au ${ }^{\mathrm{I}}$-Catalyzed $[2+2+2]$ Cycloadditions Towards Relevant Aza-heterocycles; Key Challenges
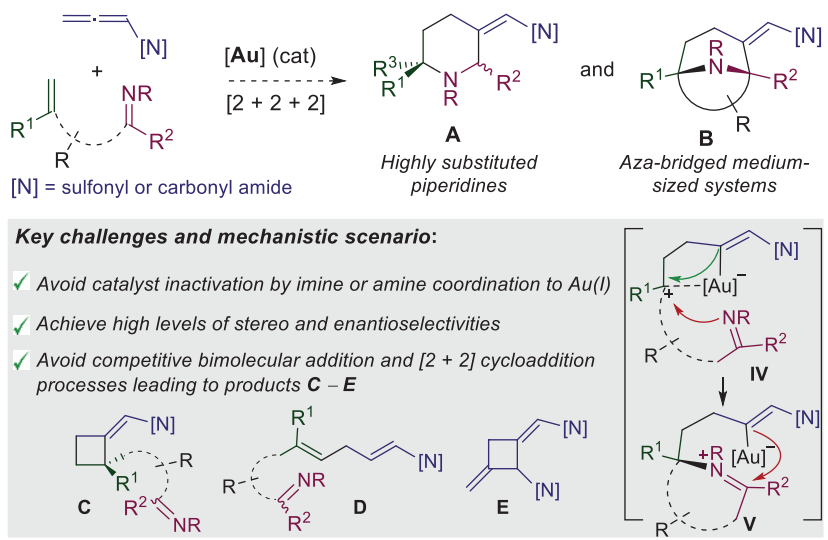

\section{RESULTS AND DISCUSSION}

Feasibility of an Intermolecular $[2+2+2]$ annulation between Allenes, Alkenes and Imines. We initially assessed the viability of a fully intermolecular formal cycloaddition by selecting as model substrates the allenamide 1a, $\alpha$-methyl styrene (2a) and a variety of imines (3) with diverse electronic and steric characteristics (Table 1 and Table S1). ${ }^{23}$ Unfortunately, despite extensive screening, none of the gold catalysts and reaction conditions provided the desired piperidines 4 . However, we observed different reactivities depending on the type of imine employed. With the benzyl imine of benzaldehyde (3a), there was not reactivity at $r t$; while after prolonged heating at $85^{\circ} \mathrm{C}$, we detected side products arising from self-polymerization of the allenamide (Table 1, entries 1 and 2). Considering that $[2+2]$ adducts like $\mathbf{5 a a}$ and $\mathbf{5 a}$, as well as the addition product $\mathbf{6 a a}$, are known to be readily formed at temperatures below $0{ }^{\circ} \mathrm{C}$ when the gold-catalyzed reaction is carried out in absence of the imines, ${ }^{11 d, 12,13}$ these preliminary results suggest that the imine component is inactivating the gold(I) complex. Indeed, with less basic imines such as the $N$-tert-butylsulfinyl derivative $\mathbf{3 b}$, we observed partial formation of these bimolecular products at $r t$; however, the desired piperidine adducts were never detected in the crude mixtures (entry 3). Similarly, using aryl imines such as $\mathbf{3 c}$, we observed the formation of complex reaction mixtures (entry 4), whereas the more bulky mesityl imine (3d) did not provide significantly better results (entry 5). Therefore, although these less basic imines did not fully inhibit the activity of the gold complex, they do not participate in the desired annulation processes. 
Table 1. Preliminary Screening of an Intermolecular $[2+2$ $+2]$ Cycloaddition $^{a}$

$$
\begin{aligned}
& \|_{\text {entry }}^{[\mathrm{N}]} \mathrm{R}^{1} / \mathrm{R}^{2} \\
& \hline 1
\end{aligned}
$$

${ }^{a}$ Conditions: Allenamide 1a (1 equiv), 2a (2 equiv) and the imine (2-5 equiv) were treated with Au1 (5 mol\%) in $\mathrm{CH}_{2} \mathrm{Cl}_{2}$ or 1,2-DCE at the indicated temperature for 2-20 h, unless otherwise noted. ${ }^{23}{ }^{b}$ Results using Au2, Au3 and Au4 were not significantly different (see Table S1). ${ }^{23}{ }^{c}$ Degradation and polymerization of $1 \mathbf{a}$ is observed. ${ }^{23 d}$ Complex mixture of several unidentified products.

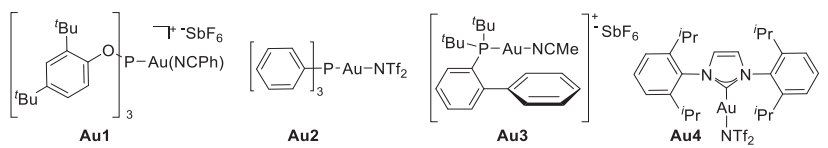

Overall, these results confirm not only the difficulties for accomplishing the designed heteroannulation, but also our initial suspects on the interference of imines with gold(I) catalysis. We next hypothesized that tethering the alkene and the imine might favor the interception of the carbocation in intermediates of type IV (Scheme 2 ), and hence drive the desired cascade annulation. Nevertheless, treatment of 1a with 7a (1.5 equiv), in the presence of Au1 (5 $\mathrm{mol} \%$ ), at room temperature, led to complete recovery of starting materials. However, heating these mixtures up to $85^{\circ} \mathrm{C}$ for $24 \mathrm{~h}$ led to traces of two new products (8aa and 9aa), the former being compatible with a formal $[2+2+2]$ adduct that holds the two phenyl substituents of the piperidine moiety in cis disposition (Scheme 3). From all other gold catalysts tested, only Au4 slightly improved the performance of Au1, to afford a still very poor 13\% yield of the indolizidine adduct 8aa (Scheme 3 and Scheme S1). ${ }^{23,24}$ Unfortunately, all attempts to increase the yield of the desired cycloadduct (8aa), by modifying the reaction conditions and/or the catalyst were unsuccessful.

Scheme 3. Preliminary Screening of a Au(I)-Catalyzed Cycloaddition using the $N$-tethered Alkenyl Imine 7 a

$$
\begin{aligned}
& \text { (1.0 equiv) } \\
& {[\mathrm{N}]=\frac{3}{3} \mathrm{Na} \text { equiv) }}
\end{aligned}
$$

At this point, we decided to tackle this poor performance by testing the reactivity of precursors containing an alkyl oxime instead of the imine (Scheme 4). We anticipated that the lower Lewis basicity of linear aliphatic aldehydes bearing $\alpha$-hydrogens..$^{25}$ Moreover, both cis and trans oxime isomers are configurationally stable and potentially accessible. ${ }^{26}$ Not less important, the $\mathrm{N}-\mathrm{O}$ bond that is present in the products should provide for further elaboration into a variety of piperidine derivatives. ${ }^{27}$

Oxime ethers (as well as esters) have been unevenly employed in transition metal catalysis, and most of their reactions involve the excision of the oxime $\mathrm{N}-\mathrm{O}$ bond (through oxidative additions or via homolytic cleavage) ${ }^{28}$ In the particular case of gold catalysis, the use of oxime ethers has been limited to a handful of isolated examples. ${ }^{29}$ On the other hand, it is striking that, despite imines have been exploited in several types of catalytic annulation reactions, oxime ethers (and esters) have been barely investigated in this type of transformations. ${ }^{30,31}$

Gratifyingly, in line with our hypothesis, treatment of a mixture of allenamide 1a and the $E$-oxime ether 10a (1.5 equiv) with the phosphite gold complex Au1 (5 mol\%), at $-15^{\circ} \mathrm{C}$, led to the desired azacycle 11aa in an excellent $85 \%$ yield, and with complete diastereoselectivity and chemoselectivity (i.e. the [2+2] adducts $\mathbf{5 a}$ ' and 12aa were not detected, Scheme 4). The configuration of the adduct 11aa, which holds the two phenyl groups in cis disposition was unambiguously determined by 1D- and 2D-NMR studies, as well as by X-ray crystallography. ${ }^{23}$ Gold complex $\mathrm{Ph}_{3} \mathrm{PAuNTf}_{2}$ (Au2) was also equally effective at this temperature $\left(-15^{\circ} \mathrm{C}\right)$, whereas with less electrophilic gold complexes, such as JohnPho$\mathrm{sAu}_{(\mathrm{NCMe}) \mathrm{SbF}_{6}(\mathbf{A u 3}) \text { or IPrAuNTf }}$ (Au4), obtaining full conversions required warming up to $0{ }^{\circ} \mathrm{C}$, and the reactions were both less efficient and chemoselective (Scheme 4). With the phosphite gold catalyst Au1, the adduct 11aa could also be obtained in good yield using just equimolar amounts of allenamide 1a and alkenyl oxime 10a, (reaction time: $0.5 \mathrm{~h}, 83 \%$ yield, Scheme 4 ).

\section{Scheme 4. Preliminary Screening using the $O$-tethered} Alkenyl Oxime 10a

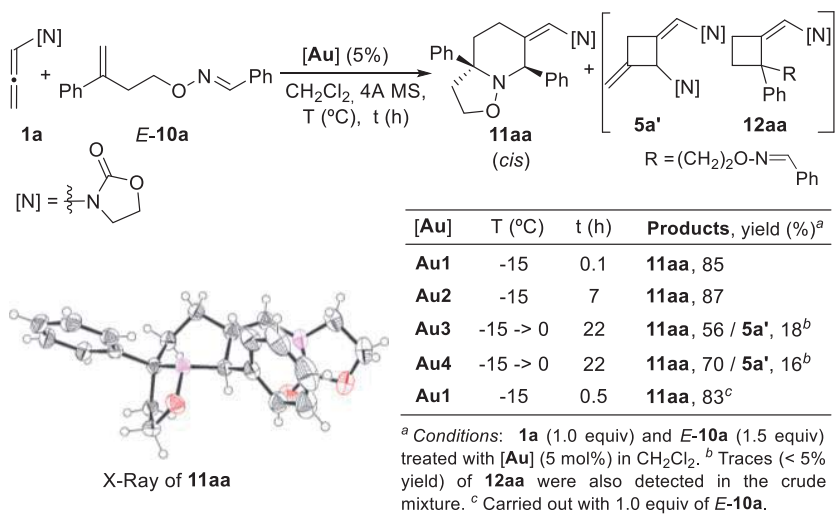

Interestingly, the reaction of $\mathbf{1 a}$ with the corresponding cis-oxime $Z$-10a, under otherwise identical reaction conditions, proceeded at a much slower rate, providing full conversion only after $22 \mathrm{~h}$ (from $-15^{\circ} \mathrm{C}$ to $r t$ ). Nonetheless, the reaction was completely chemoselective and stereospecific, providing a $60 \%$ yield of the adduct 11aa', which features the phenyl groups in trans disposition, as determined by NMR and X-ray diffraction analysis (Scheme 5). ${ }^{23}$

\section{Scheme 5. Annulation of the cis-Oxime Z-10a}

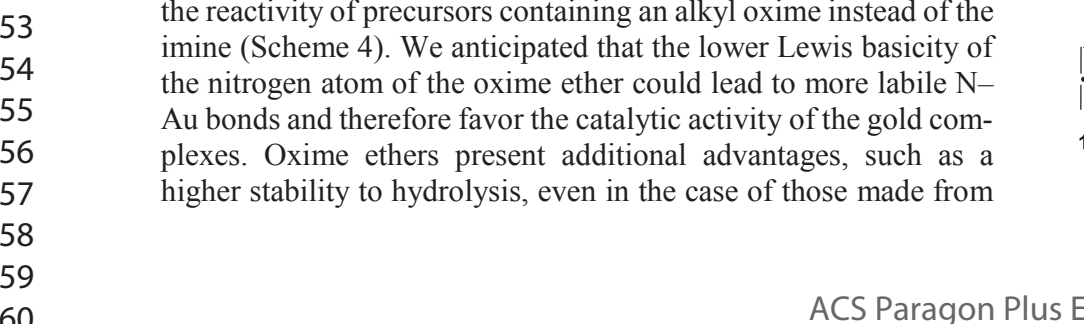
the nitrogen atom of the oxime ether could lead to more labile N$\mathrm{Au}$ bonds and therefore favor the catalytic activity of the gold complexes. Oxime ethers present additional advantages, such as a higher stability to hydrolysis, even in the case of those made from

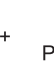<smiles>C=C(CCOC=N/N=C\c1ccccc1)c1ccccc1</smiles>

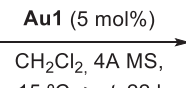

$-15^{\circ} \mathrm{C} \rightarrow r t, 22 \mathrm{~h}$

$60 \%$

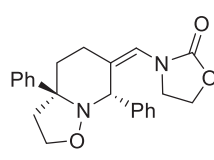

11aa' 
Interaction of Gold(I) Complexes with Imines and Oximes. To shed light into the striking differences in reactivity of imine 7a and oxime 10a, we monitored their interactions with a model gold complex such as $\mathrm{Ph}_{3} \mathrm{PAuNTf}_{2}$ (Au2) by NMR and ESI-MS (Figures S1S17). Analysis of a mixture of Au2 and 7a by ESI-MS, showed the presence of a single molecular ion peak at $m / z 708.19$, which nicely fits with the complex [7a-Au2]. Further analysis by NMR, confirmed the formation of this new complex $\left({ }^{31} \mathrm{P}-\mathrm{NMR} \delta 29.30 \mathrm{ppm}\right)$, which exhibits a downfield shift of the imine hydrogen signal in the ${ }^{1} \mathrm{H}-\mathrm{NMR}$, undoubtedly due to coordination of the gold(I) center to the imine nitrogen $\left(\Delta \delta=0.08 \mathrm{ppm}\right.$ at $0{ }^{\circ} \mathrm{C}$; Figures S1-S5 and S11). ${ }^{23,17}$ Likewise, mixing oxime E-10a and Au2 allowed to detect the analog oxime-gold(I) complex [E-10a-Au2] by ESI-MS and NMR $\left(\mathrm{m} / \mathrm{z}=710.29 ;{ }^{31} \mathrm{P}-\mathrm{NMR} \delta 28.75 \mathrm{ppm}\right.$, Figures S6-S10 and $\mathrm{S} 12)$. Interestingly, addition of the oxime derivative $E-\mathbf{1 0 a}$ to the imine-gold complex $[\mathbf{7 a}-\mathbf{A u 2}]$ at $-15^{\circ} \mathrm{C}$, did not induce any change in the mixture, as deduced by ${ }^{31} \mathrm{P}-\mathrm{NMR}$ and ESI-MS analysis (Scheme 6, eq 1, Figure S16). However, addition of the imine 7a to the oxime gold(I) complex [E-10a-Au2], induced the quantitative formation of the imine counterpart [7a-Au2] (Scheme 6, eq 2, Figure S17). Overall, these results confirm that the coordination of the imine to gold(I) is much stronger than that of the homologous oxime ether.

Scheme 6. Relative Stability of Imine- and Oxime-Gold Complexes [7a-Au2] and [E-10a-Au2]

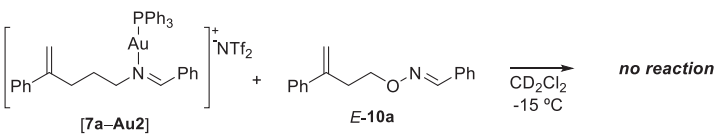

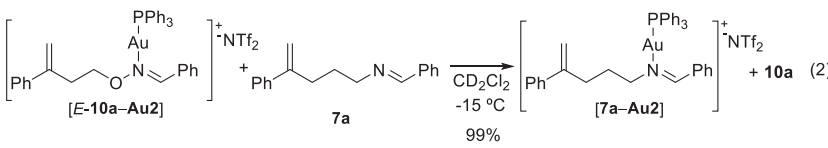

The stronger coordination of the imines to the gold(I) complex might be behind their observed lack of reactivity in the proposed annulations. Indeed, addition of the imine $7 \mathbf{a}(50 \mathrm{~mol} \%)$ to a mixture of allenamide $1 \mathbf{a}$ ( 1 equiv) and oxime ether $\mathbf{1 0 a}$ (1.5 equiv), in presence of the gold catalyst Au1 (5 mol\%), led to a complete suppression of the reactivity (Scheme 7). Even the presence of 10 $\mathrm{mol} \%$ of the imine $7 \mathrm{a}$ completely inhibited the reaction, whereas the use of equimolar amounts of Au1 and $7 \mathbf{a}(5 \mathrm{~mol} \%)$ led to a poor $17 \%$ yield of 11 aa after $24 \mathrm{~h}$ ( $50 \%$ conversion). Interestingly, in this case the reactivity could be mostly recovered by adding an additional $5 \mathrm{~mol} \%$ of catalyst Au1 to the reaction, which eventually provided a $55 \%$ yield of 11aa. A similar inhibition of the catalytic activity was observed using benzyl imine $\mathbf{3 a}$ instead of 7a, confirming the poisoning effect of alkyl imines in these gold(I)-promoted reactions (Scheme 7).

Noticeably, the higher affinity of imines to gold(I) complexes was also confirmed by DFT theoretical calculations. Thus, a theoretical characterization of the complexes of Au2 with the imine 7a and the oxime $E-\mathbf{1 0 a}$ revealed that the imine derivative, [7a-Au2], is $\sim 7$ $\mathrm{kcal} \cdot \mathrm{mol}^{-1}$ more stable than its oxime-gold counterpart $[E-\mathbf{1 0 a}-$ Au2] (Figure S18). ${ }^{23}$
Scheme 7. Inhibition of the Au(I)-Catalyzed Cycloaddition of $1 \mathrm{a}$ and $O$-Tethered Alkenyl Oxime 10a by Imines 7a and 3a

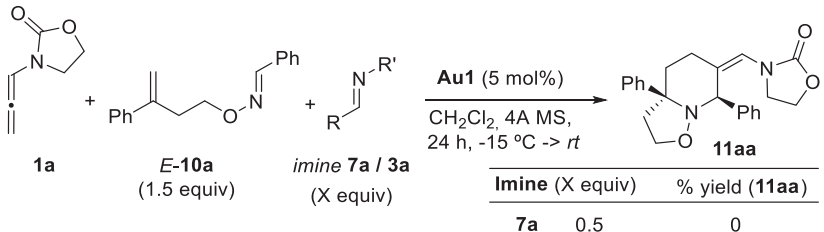

$$
\begin{aligned}
& \begin{array}{lll}
7 a & 0.1 & 0
\end{array} \\
& \begin{array}{lll}
7 a & 0.05 & 17
\end{array} \\
& \begin{array}{lll}
7 a & 0.05 & 55^{a}
\end{array} \\
& \text { 3a } 0.05 \quad 30 \\
& \text { a After } 4 \mathrm{~h} \text { at }-15^{\circ} \mathrm{C}(0 \% \text { yield of } \\
& \text { 11aa), an additional } 5 \mathrm{~mol} \% \text { of Au1 } \\
& \text { was added (overall reaction time: } 6 \mathrm{~h} \\
& \text { at }-15^{\circ} \mathrm{C} \text { ). }
\end{aligned}
$$

Scope of the Annulation between Allenes and $O$-Tethered Alkenyl Oximes. Having demonstrated the viability of engaging the alkenyl oxime ether 10a in the desired cascade annulation with allenamide 1a, we analyzed the scope of the process using other precursors (Table 2). Gratifyingly, electron-donating and electronwithdrawing groups at the aryl group of the oxime are well tolerated, and the products $11 \mathbf{a b}$ and 11 ac could be obtained with comparable efficiency. Although yields were similar in the three cases ( $80-87 \%$ yield), the formation of 11c, derived from the oxime with a more electron-deficient aryl group, proved to be faster (vide infra). ${ }^{23}$ In consonance with this result, the reaction of a glyoxalate oxime also proceeded with a high reaction rate $\left(<0.1 \mathrm{~h}\right.$ at $\left.-15^{\circ} \mathrm{C}\right)$ to provide the desired adduct 11ad with complete stereoselectivity and an excellent $87 \%$ isolated yield. In general, complete stereoselectivities in favor of the cis isomer (11) were obtained in all cases, provided that the parent oxime precursor $\mathbf{1 0}$ is configurationally $E$ pure. ${ }^{32}$ Importantly, the generation of cycloadducts fully substituted at the $\mathrm{N}$-adjacent carbon is also possible, as it is exemplified with 11ae, which was isolated with excellent yield and complete stereoselectivity. However, alkenes with a methyl, instead of a phenyl substituent, led to poorer reaction yields (11af, 13\% yield). Likely, the alkyl substituent does not provide enough stabilization to the cationic intermediate that is presumably formed after addition of the alkene of $\mathbf{1 0}$ to the gold-activated allenamide species I (vide infra).

The reaction tolerates an increase in the length of the tether connecting the alkene and the oxime. Thus, cycloadducts 11ag-11ai were obtained from the corresponding oximes with moderate to excellent yields and again complete stereoselectivity in favor of the cis isomer. On the other hand, oximes derived from aliphatic aldehydes also participated in the annulation, so that the desired product 11aj was obtained in $74 \%$ yield. Finally, the behavior of different allene partners was also tested. Thus, the cycloaddition could also be carried out with $N$-tosyl aryl allenamides, to give the desired adducts with good yields (11ba, 11bg, 11ca and 11da-11dh). The stereochemical outcome of these cycloadditions could also be confirmed by X-ray diffraction analysis of the product $11 \mathbf{d h}$ (Table $2){ }^{23}$ Finally, the scope of the annulation is not limited to $\mathrm{N}$-allenamides; thus $\mathrm{O}$-allenyl aryl ethers such as 1e $[\mathrm{OAr}=$ $\left.\mathrm{O}\left(\mathrm{pBrC}_{6} \mathrm{H}_{4}\right)\right]^{15 \mathrm{c}}$ also participated in the cascade cycloaddition to provide the corresponding adduct (i.e 11ea) in very good yield and with complete diastereoselectivity. 
Table 2. Scope of the Cycloaddition between Allenes (1) and $O$-Tethered Alkenyl Oximes (10) ${ }^{a}$

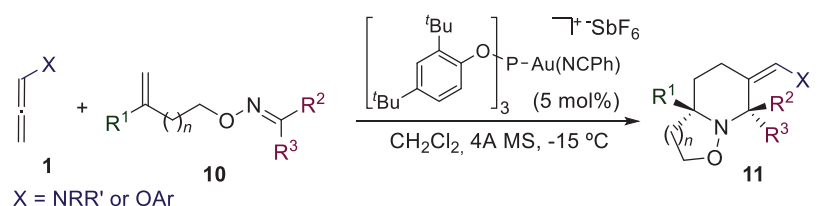

$$
\begin{aligned}
& \mathrm{X}=\mathrm{NRR} \text { or } \mathrm{OAr} \\
& \begin{array}{l}
11 \mathrm{ab}, \mathrm{R}^{2}=p(\mathrm{MeO}) \mathrm{Ph}, 80 \% \\
11 \mathrm{ac}, \mathrm{R}^{2}=p \mathrm{CF}_{3} \mathrm{Ph}, 87 \%
\end{array}
\end{aligned}
$$<smiles>CCOC(=O)C1=CCC[C@]2(c3ccccc3)C=C1OCC2</smiles><smiles>[R]C1/C(=C\N2CCOC2=O)CC[C@@]2(C)CCON12</smiles>

11af, $\mathrm{R}^{2}=p \mathrm{CF}_{3} \mathrm{Ph}, 13 \%{ }^{\mathrm{c}}$

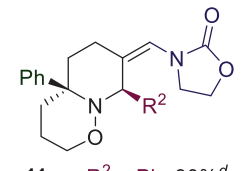

11ag, $\mathrm{R}^{2}=\mathrm{Ph}, 90 \%^{d}$ 11ah, $\mathrm{R}^{2}=p \mathrm{CF}_{3} \mathrm{Ph}, 74 \%^{d}$ 11ai, $\mathrm{R}^{2}=\mathrm{CO}_{2} \mathrm{Et}, 72 \%^{\mathrm{e}}$<smiles>O=C1OCCN1C=C1CC[C@]2(c3ccccc3)CCCON2C1CCc1ccccc1</smiles>

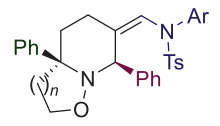
11 ba, $n=1$, $\mathrm{Ar}=\mathrm{Ph}, 55 \%^{\mathrm{b}}$ $11 \mathrm{bg}, n=2, \mathrm{Ar}=\mathrm{Ph}, 56 \%^{\dagger}$ 11ca, $n=1, \mathrm{Ar}=3,5-\mathrm{Xyl}, 62 \%$,

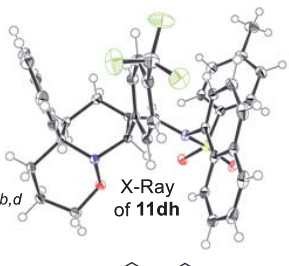

$\underbrace{1-\mathrm{Np}}_{O_{1}^{\prime}}$

11da, $n=1, \mathrm{R}^{2}=\mathrm{Ph}, 53 \%$ 11dc, $n=1, \mathrm{R}^{2}=p \mathrm{CF}_{3} \mathrm{Ph}, 62 \%$ $11 \mathrm{dd}, n=1, \mathrm{R}^{2}=\mathrm{CO}_{2} \mathrm{Et}, 74 \%$ $11 \mathrm{dg}, n=2, \mathrm{R}^{2}=\mathrm{Ph}, 69 \%$ 11dh, $n=2, \mathrm{R}^{2}=p \mathrm{CF}_{3} \mathrm{Ph}, 61 \% \quad$ 11ea, $\mathrm{Ar}=p \mathrm{BrPh}, 78 \%$

${ }^{a}$ Conditions: Allene 1 ( 1 equiv) and alkenyl oxime ether $E$-10 (1.5 equiv) were treated with Au1 (5 mol\%) in $\mathrm{CH}_{2} \mathrm{Cl}_{2}$ at $-15{ }^{\circ} \mathrm{C}$; Reaction times: 0.1 -4 h. Products dr's are $1: 0$, unless otherwise noted. ${ }^{b}$ The $E / Z$ ratio of the oxime precursor $(\mathbf{1 0})<1: 0$. Thus, traces of the trans isomer of type 11' were also detected. ${ }^{23,32 ~ c}$ Carried out from $-15^{\circ} \mathrm{C}$ to $r$, for $26 \mathrm{~h}$; Allene dimer 5a' was the main product. ${ }^{d}$ Small amounts ( $\sim 5 \%$ yield $)$ of the corresponding $\left[2+2\right.$ ] adduct of type $\mathbf{1 2}$ was also obtained. ${ }^{23}{ }^{e}$ Carried out at $-78{ }^{\circ} \mathrm{C}$; the $[2+2]$ adduct 12 ai $\left(19 \%\right.$ yield) was also obtained. ${ }^{23} f$ Carried out at 0 ${ }^{\circ} \mathrm{C}$; the adduct $\mathbf{1 2 b g}$ ( $20 \%$ yield) was also observed. ${ }^{23} 1-\mathrm{Np}=1-\mathrm{Naphthyl}$.

Cycloaddition of Allenes and $C$-Tethered Alkenyl Oximes. Having demonstrated that $O$-tethered alkenyl oximes of type $\mathbf{1 0}$ are excellent partners in the cascade cycloadditions with allenes, we wondered whether tethering the alkene and the oxime moiety via the carbon, instead of the oxygen atom, could also lead to productive annulations. This would be especially relevant because the resulting products are $a z a$-bridged medium sized carbocycles, highly appreciated, privileged scaffolds in biomedicine (Figure 1 and Scheme 2). Thus, $C$-tethered alkenyl oxime derivatives of type 14 (Table 3) were readily prepared from the corresponding carbonyl precursors in an easily scalable manner. ${ }^{23}$ For comparison purposes, we also considered analogous imines of type 13 (Table 3); however, in contrast to the oxime ethers, which are perfectly stable and easily purified, most of the attempted imines suffered from low stability. This is probably associated to the presence of $\alpha$-enolizable positions, which favor a rapid interconversion to the enamines. Indeed, only in the case of the sulfinyl imine derivative 13a, we were able to obtain pure samples to test its reactivity. For related tosyl- and aryl-imines $\mathbf{1 3 b}$ and $\mathbf{1 3} \mathbf{c}$, the reaction crudes had to be used without additional purification, to avoid decomposition of the imine.

As shown in Table 3 (entries 1-5), none of these imines (13) provided the azabicyclo[3.2.1] octane products (15). Using the imine 13a, we detected the allenamide [2+2] dimer 5a' (entries 1-3), whereas with imines $\mathbf{1 3 b}$ and $\mathbf{1 3 c}$, the starting materials were recovered (entries 4-5). In contrast, we were pleased to observe that the $O$-methyl aldoxime $E$-14a reacts efficiently with 1 a to provide the desired 8-azabicyclo[3.2.1] octane derivative 15aa in $68 \%$ yield, together with traces of the [2+2] cycloadduct 16aa (entry 6). ${ }^{33}$ Other catalysts such as Au2 and Au4 also provided the desired product, but with lower selectivities (entries 7-9). Interestingly, the cis aldoxime Z-14a did not provide the expected product; instead, we only observed decomposition of the allenamide after prolonged reaction times (entry 10). Using a 1:1 E/ Z mixture of $\mathbf{1 4 a}$, the desired product 15aa could be obtained, albeit in significantly lower yields (up to $45 \%$ yield with Au4, entries 11 and 12). The lack of the reactivity of the Z-oxime derivative is consistent with the topological requirements of the annulation process, in particular with the interception of the carbocationic intermediate of type IV by the nitrogen lone pair, which is geometrically difficult in the case of the Z-isomer of the oxime (Scheme 2).

The viability of the cycloaddition was also analyzed with the methyl ketoxime 14b (entries $13-16$ ). Gratifyingly, treatment of $E$ 14b with several gold(I) catalysts also provided the desired azabridged medium sized carbocycle 15ab. The phosphite gold catalyst Au1 and the NHC-based catalyst Au4 provided the best yields, of up to $89 \%$ (entry 13). As with the aldoxime 14a, the use of the cis isomer (Z-14b) did not lead to the desired adduct. In this case, we could observe the formation of the [2+2] adduct 16ab' (isolated in $75 \%$ yield), together with minor amounts of an acyclic hydrofunctionalization product ( $10 \%$ yield, entry 16$){ }^{23}$

Table 3. Viability of the Annulation with $C$-Tethered Alkenyl Imines (13) and Oximes (14) ${ }^{a}$

$$
\begin{aligned}
& \text { 1a } \quad \begin{array}{l}
13(\mathrm{NR} ': \text { imine, } \mathrm{R}=\mathrm{H}) \\
14(\mathrm{NR}) \text { oxime, } \mathrm{R}=\mathrm{H} \text { or } \mathrm{Me})
\end{array} \\
& {[\mathrm{N}]=2 \text {-oxazolidinone }}
\end{aligned}
$$

\begin{tabular}{|c|c|c|c|c|c|c|}
\hline entry & & $\mathrm{R}$ & 13 or 14 & {$[\mathbf{A u}]$} & $\begin{array}{l}\text { Conv } \\
\text { (\%) }\end{array}$ & Products, yield (\%) \\
\hline 1 & $\mathrm{~S}(\mathrm{O})^{t} \mathrm{Bu}$ & $\mathrm{H}$ & 13a & Au1 & 0 & - \\
\hline 2 & $\mathrm{~S}(\mathrm{O})^{t} \mathrm{Bu}$ & $\mathrm{H}$ & $13 a$ & Au1 & 100 & $\mathbf{5 a}, 24^{b}$ \\
\hline 3 & $\mathrm{~S}(\mathrm{O})^{t} \mathrm{Bu}$ & $\mathrm{H}$ & $13 a$ & Au4 & 100 & $\mathbf{5} \mathbf{a}^{\prime}, 45^{c}$ \\
\hline $4^{d}$ & $\mathrm{SO}_{2}$ tol & $\mathrm{H}$ & $13 \mathrm{~b}$ & Au1 & 0 & - \\
\hline $5^{d}$ & $p(\mathrm{MeO}) \mathrm{Ph}$ & $\mathrm{H}$ & $13 \mathrm{c}$ & Au1 & 0 & - \\
\hline 6 & $\mathrm{OMe}$ & $\mathrm{H}$ & $E-14 a$ & Au1 & 99 & 15aa, 68 / 16aa, 5 \\
\hline 7 & $\mathrm{OMe}$ & $\mathrm{H}$ & $E-14 a$ & Au2 & 99 & 15aa, $55 / 16 a a,<5$ \\
\hline 8 & $\mathrm{OMe}$ & $\mathrm{H}$ & $E-14 a$ & Au3 & 50 & $15 \mathrm{aa}, 5 / 16 \mathrm{aa},<5$ \\
\hline 9 & $\mathrm{OMe}$ & $\mathrm{H}$ & $E-14 a$ & Au4 & 99 & 15aa, 60 / 16aa, 40 \\
\hline 10 & $\mathrm{OMe}$ & $\mathrm{H}$ & $Z-14 a$ & Au1 & 99 & $-e$ \\
\hline 11 & $\mathrm{OMe}$ & $\mathrm{H}$ & 14a $(E / Z: 1: 1)$ & Au1 & 92 & 15aa, 35 \\
\hline 12 & $\mathrm{OMe}$ & $\mathrm{H}$ & 14a $(E / Z: 1: 1)$ & Au4 & 99 & 15aa, 45 / 16aa, 10 \\
\hline 13 & $\mathrm{OMe}$ & $\mathrm{Me}$ & $E-14 b$ & Au1 & 99 & 15ab, 89 / 5a', 6 \\
\hline 14 & $\mathrm{OMe}$ & $\mathrm{Me}$ & $E-14 b$ & Au4 & 99 & $15 \mathbf{a b}, 60 / 16 \mathbf{a b}, 5$ \\
\hline 15 & $\mathrm{OMe}$ & $\mathrm{Me}$ & $E-14 b$ & Au2 & 99 & 15ab, $26 / \mathbf{5 a}, 14$ \\
\hline 16 & $\mathrm{OMe}$ & $\mathrm{Me}$ & $Z-14 b$ & Au1 & 99 & 16ab', 75 / 17ab, 10 \\
\hline
\end{tabular}

${ }^{a}$ Conditions: Allenamide $\mathbf{1 a}$ ( 1 equiv) and $\mathbf{1 3}$ or $\mathbf{1 4}$ (1.5 equiv) were treated with the gold catalyst $[\mathbf{A u}](5 \mathrm{~mol} \%)$ in $\mathrm{CH}_{2} \mathrm{Cl}_{2}$ at $r t$ for $1 \mathrm{~h}$, unless otherwise noted. ${ }^{b}$ Carried out in toluene from $r t$ to $85{ }^{\circ} \mathrm{C}$ for $1 \mathrm{~h} .{ }^{c}$ Carried out in toluene at $r t$ for $1 \mathrm{~h} .{ }^{d}$ The crude mixture containing the imine $\mathbf{1 3}$ was used without purification. ${ }^{e}$ After $24 \mathrm{~h}$, decomposition of $1 \mathrm{a}$ was just observed. 
Having demonstrated the viability of the tandem annulation process, we checked its scope (Table 4). Gratifyingly, the reaction was not limited to the aldoxime and ketoxime precursors $14 \mathbf{a}$ and $\mathbf{1 4 b}$; a methyl oxamate also provided the desired product $15 \mathrm{ac}$, in a good $71 \%$ yield. Notably, the reaction works with oxime derivatives having substituents at the oxygen atom others than methyl $\left(\mathrm{R}^{4}\right)$. Therefore, the reaction worked well with substrates bearing trifluoroethyl, benzyl and acyl substituents such as acetyl, benzoyl or pivaloyl, to give the expected products in yields varying from 65 to $84 \%$ (15ad-15ah).

The annulation tolerates aryl substituents other than phenyl at the alkene moiety and, remarkably, it is also viable with an alkenyloxime substrate bearing a methyl at this internal position of the alkene. Therefore, azacyclic products $\mathbf{1 5} \mathbf{a j}$ - 15am were obtained in yields varying from 41 to $90 \%$. We also investigated the influence of an additional methyl substituent at the terminal position of the phenyl alkene moiety $(\mathbf{1 4} \mathbf{i}$, alkene $E / Z$ ratio $=1.1: 1)$. In agreement with previous results for the [2+2] cycloadditions, ${ }^{11 \mathrm{~d}}$ we only observed the reaction of the trans isomer $(E-14 i)$, which efficiently afforded the azabicylic product 15ai as a single diastereoisomer ( $72 \%$ yield)

Moreover, other $\mathrm{N}$-allenyl amides or $\mathrm{O}$-allenyl ethers can also participate as annulation partners to give the expected products $\mathbf{1 5 b b}$ - 15fb. Particularly efficient were the cycloadditions of the allenyl ether 1e, which provided the corresponding tropane derivatives 15ej - 15el with yields up to $94 \%$. The cascade cycloaddition is also effective for the synthesis of benzotropane derivatives such as 15an. Importantly, oximes bearing a one-carbon longer connecting tether also participated in the process, affording the corresponding aza-bridged cyclooctanes (15ao, 15 bo and 15eo) in good yields, varying from 68 to $88 \%$. Finally, the synthesis of the azabicyclo[4.3.1]decane 15ap, featuring an aza-bridged nine-membered carbocycle was also possible ( $40 \%$ yield), albeit in this case the crude reaction mixture also contained substantial amounts of the competitive [2+2] adduct 16ap and the acyclic addition product 17ap..$^{23}$
Table 4. Au(I)-Catalyzed Formal $[2+2+2]$ Cycloaddition of Allenes (1) and $C$-Tethered Alkenyl Oximes (14) ${ }^{a}$
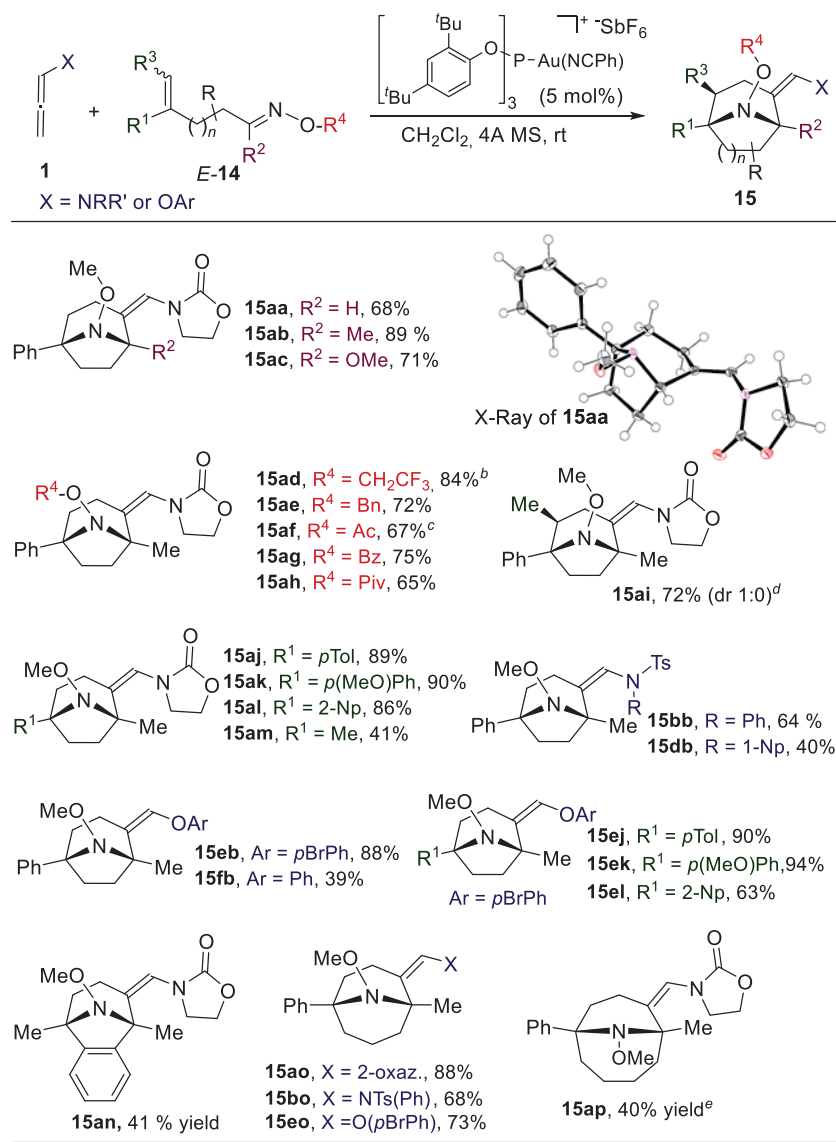

${ }^{a}$ Conditions: Allene 1 ( 1 equiv) and $E$-alkenyl oxime 14 (1.5 equiv) were treated with Au1 (5 mol\%) in $\mathrm{CH}_{2} \mathrm{Cl}_{2}$ at $r$ (reaction times: from $0.1 \mathrm{~h}$ to 6 h). ${ }^{23}$ Products are mixtures of axial and equatorial $N$-invertomers, with ratios varying from $1.1: 1$ (15ah) to $1: 0$ (15ae) (see the Supp. Info. for each particular case). Isolated yields. ${ }^{b} 3.0$ equiv of oxime $14 d(E / Z=2.1: 1)$ were used. ${ }^{c}$ Carried out at $-30{ }^{\circ} \mathrm{C} .{ }^{d} 3.0$ equiv of oxime 14i (alkene $E$ / $Z$ ratio $=1.1: 1) .{ }^{e}$ The $[2+2]$ adduct 16 ap $(30 \%$ yield $)$ and an acyclic addition product 17ap ( $18 \%$ yield, see the S.I.) were also obtained. ${ }^{23} 2-\mathrm{Np}=2$-Naphthyl.

Synthetic Elaboration of the Cycloadducts. The presence of the exo-enamide and the alkoxyamine moieties provides for further elaboration of the azabicyclic adducts (Scheme 8). For instance, treatment of $15 \mathrm{ab}$ with $\mathrm{RuCl}_{3} / \mathrm{NaIO}_{4}$ cleanly afforded the corresponding ketone, $\mathbf{1 8 b}$, in $84 \%$ yield. Alternatively, hydrolysis of the enamide with $\mathrm{HCl}$ (aq) efficiently provides the aldehyde 19b, whereas a dihydroxylation reaction with $\mathrm{OsO}_{4}$ leads to the $\alpha$-hydroxy aldehyde $\mathbf{2 0 b}$ as a single diastereoisomer, in excellent yield. On the other hand, treatment of $\mathbf{1 5} \mathbf{a b}$ with $\mathrm{SeO}_{2}$ provided the $\alpha, \beta-$ unsaturated aldehyde $\mathbf{2 1 b}$ in $83 \%$ yield. ${ }^{34}$ Noticeably, this efficient transformation paves the way for introducing further substituents at the key C4-position of the tropane skeleton by means of Michael additions of different nucleophiles. Finally, the N-OMe group can be readily cleaved by treatment with $\mathrm{Zn} / \mathrm{AcOH}$ to give the corresponding secondary amine (22ab) in an excellent $88 \%$ yield.

With respect to the piperidine scaffolds, treatment of 11aa with $\mathrm{Zn}$ / AcOH provided a 90\% yield of the piperidine 23aa (Scheme 9). Piperidines like 23ae, featuring fully substituted centers at their nitrogen-adjacent positions, can also be readily obtained. Interestingly, piperidine $23 \mathrm{ag}$ could be easily transformed into the indolizidine derivative 8aa by treatment with $\mathrm{MsCl}$ and $\mathrm{Et}_{3} \mathrm{~N}$. On the other hand, treatment 11 aa with $\mathrm{Pd}(\mathrm{OH})_{2}$ under $\mathrm{H}_{2}(1 \mathrm{~atm})$ at $r$, provided 
the hydrogenated product 24aa. Finally, as in the case of the tropane derivatives, treatment of 11 aa with $\mathrm{OsO}_{4}$ afforded the corresponding $\alpha$-hydroxy aldehyde (25a) in good yield and with almost perfect diastereoselectivity (Scheme 9).

\section{Scheme 8. Synthetic Elaboration of Azabicycles of Type $15^{a}$}

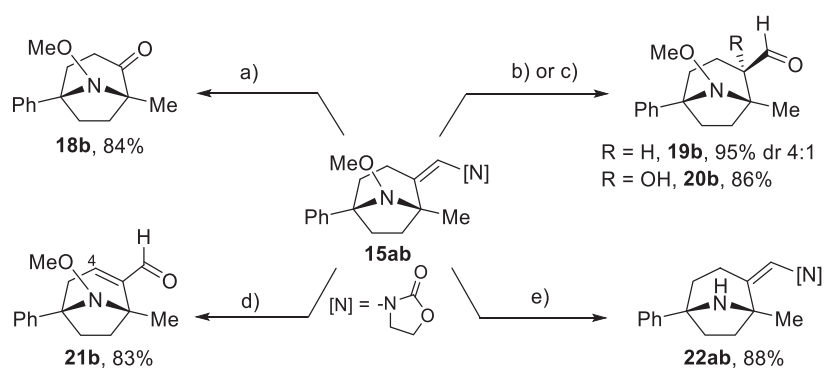

${ }^{a}$ Conditions: a) $\mathrm{RuCl}_{3}, \mathrm{NaIO}_{4}, \mathrm{MeCN} / \mathrm{EtOAc} / \mathrm{H}_{2} \mathrm{O}, r t, 84 \%$ yield; b) $\mathrm{HCl}$ $(6 \mathrm{~N}), \mathrm{CHCl}_{3}$, reflux, $95 \%$ yield, dr 4:1; c) $\mathrm{OsO}_{4}(6 \%), \mathrm{NMO}$, Acetone / $\mathrm{MeCN}, \mathrm{H}_{2} \mathrm{O}, r t, 86 \%$ yield; d) $\mathrm{SeO}_{2}, 1$,4-dioxane, reflux, $83 \%$ yield; e) $\mathrm{Zn}$, $\mathrm{AcOH} / \mathrm{H}_{2} \mathrm{O}(2: 1), 100{ }^{\circ} \mathrm{C}, 88 \%$ yield. $[\mathrm{N}]=2$-oxazolidinone.

Scheme 9. Synthetic elaboration of azabicycles of type $11^{a}$

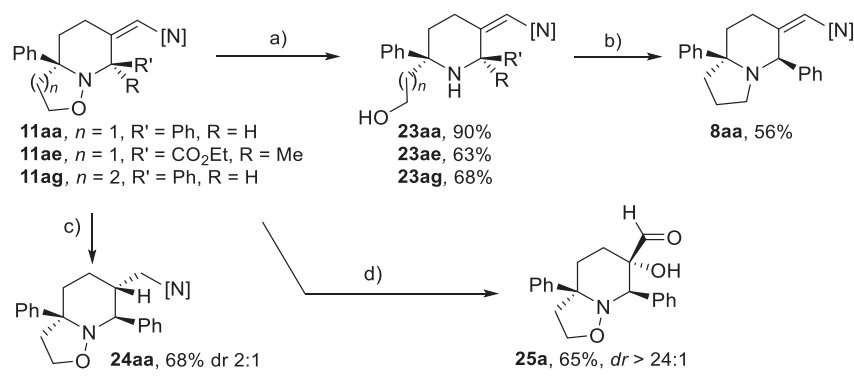
$\mathrm{Et}_{3} \mathrm{~N}, \mathrm{CH}_{2} \mathrm{Cl}_{2},-20{ }^{\circ} \mathrm{C}->0{ }^{\circ} \mathrm{C}, 56 \%$ yield; c) $\mathrm{Pd}(\mathrm{OH})_{2}, \mathrm{H}_{2}(1 \mathrm{~atm}), \mathrm{MeOH}$, $r t, 68 \%$ yield, dr $2: 1$; d) $\mathrm{OsO}_{4}$ (cat.), $\mathrm{NMO}$, Acetone / $\mathrm{MeCN}, \mathrm{H}_{2} \mathrm{O}, r t, 65 \%$ yield, $\mathrm{dr}>24: 1 ;[\mathrm{N}]=2$-oxazolidinone.

Preliminary studies on Enantioselective Variants. Overall, the above reaction manifolds highlight the great potential and versatility of alkenyl-containing oximes of type $\mathbf{1 0}$ and $\mathbf{1 4}$ for a straightforward and versatile synthesis of aza-bridged medium-sized carbocycles and piperidine scaffolds. An additional, major step forward in this research would consist of the development of enantioselective variants. In general, direct enantiocatalytic approaches to aza-bridged medium sized carbocycles are very scarce and limited to the synthesis of products with the tropane azabicyclic core. ${ }^{9}$ Moreover, we are not aware of approaches that allow the preparation of optically active piperidines and aza-bridged medium-sized carbocycles heavily substituted at the $\alpha$-positions of the $\mathrm{N}$-atom.

A preliminary screening of chiral gold(I) complexes led us to identify the phosphoramidite-gold complex $(S, R, R)$-Au5/AgNTf 2 as a suitable catalyst to achieve asymmetric cycloadditions between $C$ tethered alkenyl oximes of type $E-\mathbf{1 4}$ and $N$-tosyl allenamides (e.g. 1b) ${ }^{23}$ Thus, as shown in the Table 5 , the cycloaddition of $N$-tosyl phenyl allenamide $1 \mathrm{~b}$ with alkenyl $O$-methyl oxime $E$-14b proceeded smoothly at $0{ }^{\circ} \mathrm{C}$ to provide after $4 \mathrm{~h}$, the desired azabridged carbocycle (15bb) in $65 \%$ yield and with an enantiomeric ratio (er) of $83: 17$. Decreasing the reaction temperature to $-15^{\circ} \mathrm{C}$ yield. However, the use of the allenamide 1d, bearing a 1-naphthyl ring at the tosyl amide, led to a better yield $(\mathbf{1 5 d b}, 61 \%)$ and a slightly better er. Likewise, other $O$-methyl oximes, featuring different substituents at the aryl moiety of the alkene, also provided their respective tropanic products $(\mathbf{1 5} \mathbf{b j} \mathbf{- 1 5} \mathbf{b l})$ with good yields at -
${ }^{a}$ Conditions: a) $\mathrm{Zn}, \mathrm{AcOH} / \mathrm{H}_{2} \mathrm{O}(2: 1), 100{ }^{\circ} \mathrm{C}, 63-90 \%$ yield; b) $\mathrm{MsCl}$, brought only a marginal increase of the er, and compromised the

$15{ }^{\circ} \mathrm{C}(70-79 \%)$, and good er's, which varied from $86: 14$ (15bj) to $92: 8$ (15bk).

Fine tuning of the alkenyl oxime partner (14) allowed to further improve the enantioselectivity. In particular, the use of $O$-benzoyl oximes, instead of the $O$-methyl counterparts, provided for slightly but consistently higher enantiomeric ratios [e.g. 15dg (90:10 er) vs $\mathbf{1 5 d b}(87: 13 \mathrm{er})]$. Along these lines, the cycloaddition of $N$-tosyl phenyl allenamide (1b) with several $O$-benzoyl oximes bearing electron donating substituents at the aryl moiety of their alkenes, afforded their respective aza-bridged carbocycles with excellent enantiomeric ratios, which varied from $94: 6$ (15br and 15bs) to 95:5 (15bq and 15bt). Importantly, the enantioselective variant is not limited to the synthesis of aza-bridged seven-membered rings; indeed, the eight-membered carbocycle 15bp could also be obtained with moderate yield and with an enantiomeric ratio of 90:10.

We then checked whether the same catalytic system could also be successful in the tandem annulation between allenamides and $O$ tethered oximes of type $\mathbf{1 0}$. Gratifyingly, the cycloaddition of $\mathbf{1 b}$ and $10 \mathrm{a}$ could be efficiently carried out at $-30^{\circ} \mathrm{C}$ to exclusively afford the desired piperidine (11ba) in good yield and with a good enantiomeric ratio of 87:13 (Table 5). This could be further improved by using the $N$-tosyl-1-naphthyl allenamide 1d, so that product 11da was obtained in 83\% yield and an excellent 93:7 er. Importantly, the complex $(S, R, R)$ - $\mathbf{A u 5} / \mathrm{AgNTf}_{2}$ also catalyzes the cycloaddition of allenamide 1d with other alkenyl oximes such as $10 \mathrm{c}$ and $\mathbf{1 0 g}$, to provide the corresponding azacycles (11dc and 11dg) with good yields and er's of 92:8 and 91:9, respectively.

Finally, we also checked whether a cis oxime like Z-10a could also participate in an enantioselective annulation. Gratifyingly, its cycloaddition with $\mathbf{1 b}$, catalyzed by $(S, R, R)$ - $\mathbf{A u 5} / \mathrm{AgNTf}_{2}$, gave the expected trans piperidine bicyclic system 11ba' in $81 \%$ yield and 87:13 er, identical to that obtained for 11ba, from E-10a. Similarly, other cis oxime precursors of type Z-10 also provided their corresponding adducts with the same er than their respective E-isomers. ${ }^{23,35}$

Table 5. Preliminary Enantioselective Au(I)-Catalyzed Cycloaddition of Allenamides and $C$ - and $O$-Tethered Oximes ${ }^{a}$
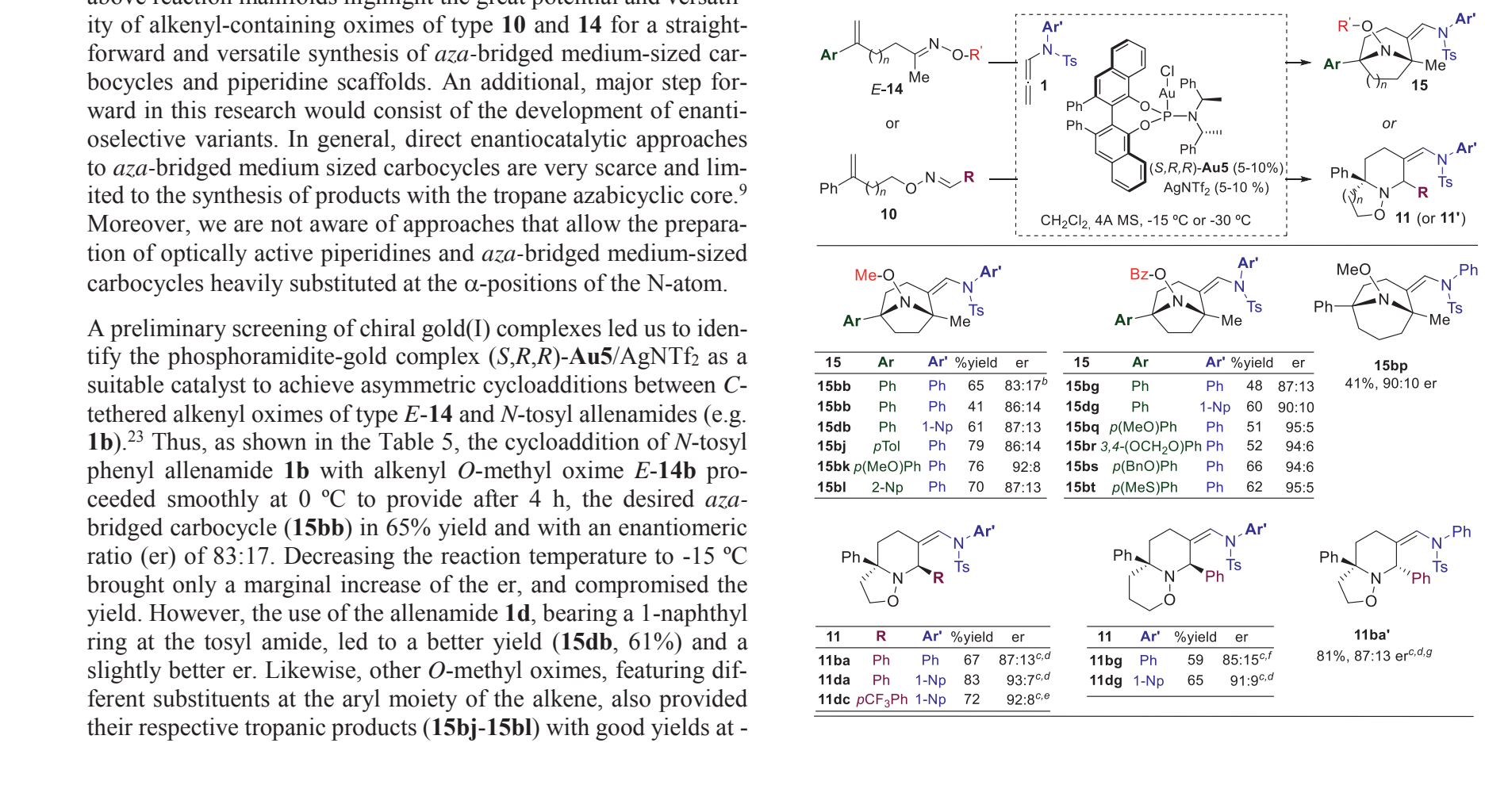

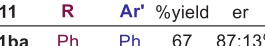

$\begin{array}{lllll}11 \text { da } & \mathrm{Ph} & 1-\mathrm{Np} & 83 & 93: 7^{c, d}\end{array}$

1dc $p \mathrm{CF}_{3} \mathrm{Ph} 1-\mathrm{Np} \quad 72 \quad 92: 8^{\mathrm{c}, \mathrm{e}}$ 
${ }^{a}$ Conditions: Allenamide 1 (1 equiv) and E-alkenyl oxime (10 or $\mathbf{1 4}, 1.5$ equiv) were treated with $(S, R, R)$-Au5 $(10 \mathrm{~mol} \%) / \operatorname{AgNTf}_{2}(10 \mathrm{~mol} \%)$ in $\mathrm{CH}_{2} \mathrm{Cl}_{2}$ at $-15^{\circ} \mathrm{C}$ (reaction times: $0.5-6 \mathrm{~h}$ ), ${ }^{23}$ unless otherwise noted. ${ }^{b} \mathrm{Car}-$ ried out at $0{ }^{\circ} \mathrm{C}$ with $5 \mathrm{~mol} \%$ of catalyst for $4 \mathrm{~h} ;{ }^{c}$ Carried out with $5 \mathrm{~mol} \%$ of catalyst. ${ }^{d}$ Carried out at $-30{ }^{\circ} \mathrm{C}$ for $17 \mathrm{~h} .{ }^{e}$ Carried out at $-50{ }^{\circ} \mathrm{C}$ for $5 \mathrm{~h} .{ }^{f}$ Carried out at $0{ }^{\circ} \mathrm{C}$ for $0.5 \mathrm{~h}$; A [2+2] adduct $(\mathbf{1 2 b g})$ was also obtained in $15 \%$ yield and $93: 7$ er. ${ }^{g}$ Carried out with Z-10a instead of E-10a. $\mathrm{Np}=$ naphthyl.

Absolute Configuration and Mechanistic Interpretations. X-ray analysis of the absolute configuration of the cis and trans cycloadducts 11 ba and 11 aa' confirmed that both piperidine type of scaffolds share the same absolute configuration of the chiral center generated at the position labeled as C-1 (Figure 2). Moreover, the absolute configuration of the homologous stereocenter in the tropane derivative 15gb is also the same. Therefore, both types of cascade annulations most likely share the same enantio-determining step, namely, the addition of the alkene moiety to the gold activated allenamide (zwitterionic intermediate I, Scheme 10) to afford intermediate species of type IV or VI (Scheme 10). These species should not be viewed as standard benzylic carbocations but rather as configurationally stable carbocations, in which the rotation around the $\mathrm{C}-1-\mathrm{C}-2$ bond is restricted due to an electrostatic interaction between $\mathrm{C}-1$ and the gold(I) atom. ${ }^{14,}{ }^{36}$ Then, an intramolecular stereospecific attack of the oxime nitrogen would produce the corresponding iminium species $\mathbf{V}$ and VII, respectively. A subsequent stereospecific aza-Prins cyclization in VII would provide the epimeric piperidines 11 (from the trans oxime E-10) and 11' (from the $Z$-counterpart), both presenting the same enantiomeric excess (Scheme 10). ${ }^{23}$ Likewise, a related aza-Prins cyclization in cyclic iminium $\mathbf{V}$ affords the tropane derivatives 15, which are obtained with similar er values to piperidines 11 / 11', as well as with the same absolute configuration at $\mathrm{C}-1$.

When the interception of the C-1 carbocation by the oximic nitrogen is not efficient, competitive [2+2] cycloadducts of type $\mathbf{1 2}$ (or 16) can be obtained. Curiously, these cyclobutanes are regularly obtained with slightly higher er's than their respective [2+2+2] counterparts. ${ }^{37,23}$ Based on previous results on enantioselective [2 +2] cycloadditions of $N$-sulfonyl allenamides, ${ }^{38}$ we can additionally propose that these cyclobutane side-products are obtained with the opposite absolute configuration at their homologue stereocenter, when the same chiral catalyst is used to carry out the cycloaddition $\left[(S, R, R)\right.$-Au5 / $\left.\mathrm{AgNTf}_{2}\right]$.

Overall, these results strongly suggest that the three pathways, towards piperidines $(\mathbf{1 1} / \mathbf{1 1}$ '), tropanes 15 and cyclobutanes (12/ 16), share the same enantiodetermining step (formation of species IV/VI, Scheme 10); however, the asymmetric induction attained in these intermediates is slightly eroded during their transformation into species $\mathbf{V}$ or VII. This step must involve an attack anti with respect to the $\mathrm{Au}(\mathrm{I})$ atom, ${ }^{13 \mathrm{a}}$ so that cyclobutanes (12 and 16) and the $[2+2+2]$ adducts $(\mathbf{1 1}$ and $\mathbf{1 5})$ are obtained with opposite absolute configurations at their shared stereocenter (C-1).
Figure 2. X-ray diffraction analysis of enantiorich 11ba, 11 aa', $15 \mathrm{gb}$, showing the absolute configuration ${ }^{39}$

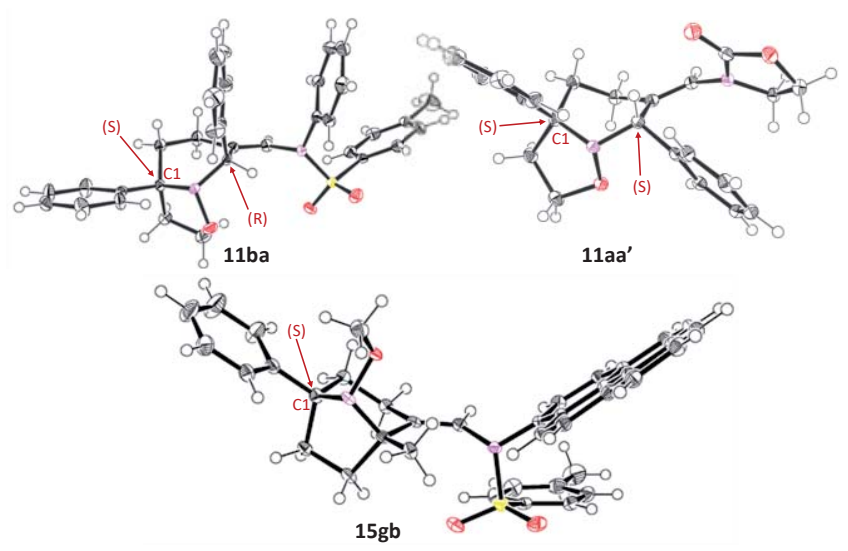

Scheme 10. Mechanistic Hypothesis Accounting for the Observed Stereoselectivity

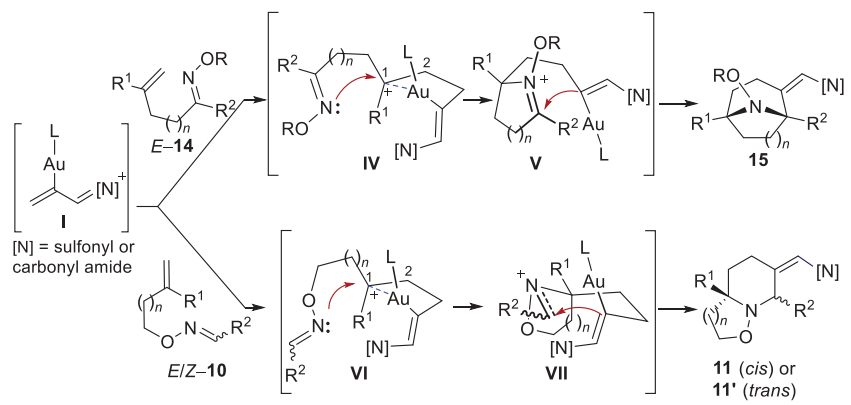

While the mechanistic profiles outlined in Scheme 10 seem appropriate to describe the annulations, there are several experimental observations that deserve further attention and interpretation. As shown in Scheme 11 (eq 1), there is a great difference in reaction rates for oxime ethers Z-10a and E-10a (full conversion of E-10a after $0.1 \mathrm{~h}$ at $-15^{\circ} \mathrm{C} v s 22 \mathrm{~h}$ at $r$ for $\left.Z-10 a\right)$. Remarkably, adding a small proportion of the cis-oxime $Z-10$ a to $E$-10a (final $E / Z$ ratio of 11:1) causes a drastic reduction of the reaction rate (from $0.1 \mathrm{~h}$ to $5 \mathrm{~h}$ for full conversion at $-15^{\circ} \mathrm{C}$ ). These results suggest that the cis-oxime Z-10a is inhibiting the reactivity, likely because of a stronger coordination to the $\mathrm{Au}(\mathrm{I})$ complex, which decreases the effective concentration of an active gold(I) catalyst in the reaction media. On the other hand, when a 1:1 mixture of $E$ - and Z-10a is employed, the reaction required $20 \mathrm{~h}$ at $r t$ for completion, and led to a $1.6: 1$ ratio of 11 aa and 11 aa' ( $75 \%$ global yield, Scheme 11 , eq 1). Since the trapping of intermediate $\mathbf{I}$ by the alkene moiety of $\mathbf{1 0 a}$, or the interception of the carbocation in VI by the oximic nitrogen to generate VII should not be significantly influenced by the $E / Z$ stereochemistry of the oxime moiety, it can be anticipated that this 1.6:1 ratio is essentially reflecting the different rates of the azaPrins cyclizations of the Z- and E-oxime intermediates of type VII. ${ }^{40}$

As previously commented, the reaction of alkenyl oxime E-10c, which bears an electron withdrawing $p \mathrm{CF}_{3}$ at the aryl substituent, is significantly faster than that of E-10a (Scheme 11, eq 2). This could potentially be explained either in terms of the weaker gold coordination ability of the oximic nitrogen of $10 \mathrm{c}$ (due to the withdrawing effect of the $\mathrm{pCF}_{3}$ substituent), or on the basis of a faster aza-Prins cyclization of the more electrophilic iminium intermediate (VII) derived from 10c. ${ }^{41}$ Notably, when a $1: 1$ mixture of $E$ 10a and $E-10 \mathbf{c}$ was treated under standard reaction conditions, a 1.3 : 1 mixture of the products in favor of 11aa was obtained $(90 \%$ 
global yield, Scheme 11, eq 2). Therefore, when the effective concentration of the gold(I) catalyst is the same for both substrates, the oxime $E-10 a$, equipped with the more basic nitrogen, reacts faster. This suggests that the nucleophilic interception of the carbocation of VI exerts a higher influence than the aza-Prins cyclization on the overall rate of the process, ${ }^{42}$ so that the different rates of 10a and $10 \mathrm{c}$ are essentially due to their dissimilar coordination strengths to the gold(I) complex.

Related electronic effects of the oxime counterpart are observed in the assembly of the aza-bridged systems. Thus, in independent experiments, the reaction of the less coordinating $O$-benzoyl oxime $\mathbf{1 4 g}$ was significantly faster than that of the $O$-methyl derivative 14b (0.1 h vs $4 \mathrm{~h}$, Scheme 11, eq 3$)$. Additionally, when a 1:1 mixture of both oximes was used, a $1: 1$ mixture of the products, 15ab and 15ag, was obtained. These results confirm that the step from IV to $\mathbf{V}$ has also a higher influence than the aza-Prins cyclization on the rate of the process that leads to the tropanic scaffolds (15).

\section{Scheme 11. Mechanistic experiments}
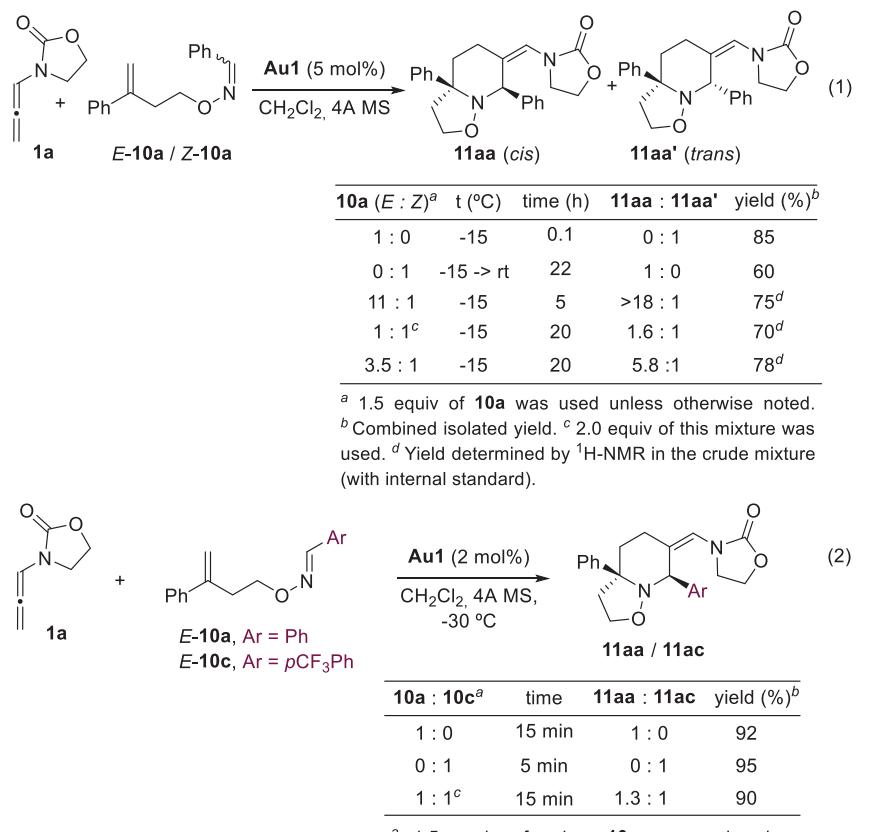

a 1.5 equiv of oxime 10 was used unless otherwise noted. ${ }^{b}$ Determined by ${ }^{1} \mathrm{H}-\mathrm{NMR}$ in the crude mixture (with internal standard). ${ }^{c} 20$ equiv of this mixture were used.
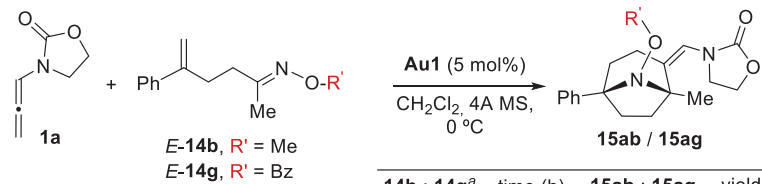

\begin{tabular}{cccc}
\hline $\mathbf{1 4 b}: \mathbf{1 4}^{a}$ & time $(\mathrm{h})$ & $\mathbf{1 5 a b}: \mathbf{1 5} \mathbf{a g}$ & yield $(\%)^{b}$ \\
\hline $1: 0$ & 4 & $1: 0$ & 90
\end{tabular}

$\begin{array}{llll}1: 0 & 4 & 1: 0 & 90 \\ 0: 1 & 0.1 & 0: 1 & 79\end{array}$

\begin{tabular}{llll}
$1: 1^{c}$ & 2.5 & $1: 1$ & 92 \\
\hline
\end{tabular}

a 1.5 equiv of oxime 14 was used unless otherwise noted. ${ }^{b}$ Determined by ${ }^{1} \mathrm{H}$-NMR in the crude mixture (with internal standard). ${ }^{c} 2.0$ equiv of this mixture were used.

\section{CONCLUSION}

To conclude, we have developed a new approach to the straightforward construction of piperidine scaffolds from readily available alkenyl-tethered oximes and $\mathrm{N}$-allenamides, using a gold-catalyzed formal $[2+2+2]$ annulation. Depending on the topology of the tethers connecting the oxime and the alkenyl moieties, the strategy provides either piperidine products or tropane-like azabicyclic systems. The annulations have a significant scope and versatility, and the resulting products are amenable of divergent elaboration in synthetically relevant manners. We also demonstrated the viability of achieving enantioselective versions, and provided mechanistically relevant experimental data that confirm the relevance of balancing the nucleophilic character and the gold coordinating ability of the $\mathrm{sp}^{2}$-nitrogen atoms of the oxime units for obtaining successful results. Our discoveries bring new opportunities in the area of gold catalysis, especially for the development of methodologies that involve the use of reaction partners equipped with nitrogen atoms.

\section{Supporting Information}

Full experimental procedures, complementary mechanistic studies, optimization of the catalysts and characterization of all new compounds, including ${ }^{1} \mathrm{H}-,{ }^{13} \mathrm{C}-\mathrm{NMR}$ spectra, MS and HPLC traces. This material is available free of charge via the Internet at http://pubs.acs.org.

\section{AUTHOR INFORMATION}

\section{Corresponding Author}

Prof. J. L. Mascareñas. joseluis.mascarenas@usc.es,

Dr. F. López.: fernando.lopez@csic.es

\section{ORCID}

José L. Mascareñas: 0000-0002-7789-700X

Fernando López: 0000-0002-0235-6858

\section{Author Contributions}

$\$$ These authors contributed equally.

\section{Notes}

The authors declare no competing financial interests.

\section{ACKNOWLEDGMENT}

This work received financial support from the Spanish MINECO (SAF2016-76689-R, CTQ2017-84767-P, FPU fellowship to I.V. and J.F.C), the Xunta de Galicia (ED431C 2017/19, 2015-CP082, Centro Singular de Investigación de Galicia accreditation 20162019 ED431G/09 and predoctoral fellowship to D.C.M.), the ERDF, ERC (Adv. Grant No. 340055) and the Orfeo-Cinqa network (CTQ2016-81797-REDC). Dr. Rebeca García-Fandiño is acknowledged for her contribution to DFT studies.

\section{REFERENCES}

(1) (a) Comins, D. L.; Joseph S. P. In Advances in Nitrogen Heterocycles, Vol. 2. Moody, C. J., Ed.; JAI, Greenwich CT, 1996, pp. 251-294. (b) Eicher, T.; Hauptmann, S.; Speicher, A. The Chemistry of Heterocycles: Structures, Reactions, Synthesis, and Applications, Wiley: Weinheim, Germany, 2013. (c) Taylor, R. D.; MacCoss, M.; Lawson, A. D. G. Rings in Drugs. J. Med. Chem. 2014, 57, 5845-5859. (d) Lovering, F.; Bikker, J.; Humblet, C. Escape from Flatland: Increasing Saturation as an Approach to Improving Clinical Success. J. Med. Chem. 2009, 52, 6752-6756.

(2) (a) O'Hagan, D. Pyrrole, Pyrrolidine, Pyridine, Piperidine and Tropane Alkaloids. Nat. Prod. Rep. 2000, 17, 435-446. (b) Strunz, G. M.; Findlay, J. A. Pyridine and Piperidine Alkaloids. In The Alkaloids: Chemistry and Pharmacology. Brossi, A., Ed.; Academic Press, 1985; Vol. 26, pp 89-183. (c) Welsch, M. E.; Snyder, S. A.; Stockwell, B. R. Privileged Scaffolds for Library Design and Drug Discovery. Curr. Opin. Chem. Biol. 2010, 14, 347-361. (d) Vitaku, E.; Smith, D. T.; Njardarson, J. T. Analysis of the Structural Diversity, Substitution Patterns and Frequency of Nitrogen Heterocycles Among U.S. FDA Approved Pharmaceuticals. J. Med. Chem. 2014, 57, 10257-10274.

(3) For reviews on the synthesis of piperidines, see: (a) Subba Reddy, B. V.; Nair, P. N.; Antony, A.; Lalli, C.; Grée, R. The Aza-Prins Reaction in the Synthesis of Natural Products and Analogues. Eur. J. Org. Chem. 2017, 2017, 1805-1819. (b) Cossy, J. Selective Methodologies for the 
Synthesis of Biologically Active Piperidinic Compounds. Chem. Rec. 2005, 5, 70-80. (c) Buffat, M. G. P. Synthesis of Piperidines. Tetrahedron 2004, 60, 1701-1729. (d) De Risi, C.; Fanton, G.; Pollini, G. P.; Trapella, C.; Valente, F.; Zanirato, V. Recent Advances in the Stereoselective Synthesis of trans-3,4-Disubstituted-Piperidines: Applications to (-)-Paroxetine. Tetrahedron: Asymmetry 2008, 19, 131-155. (e) Francois-Xavier, F.; Jacques, L. Recent Advances in the Total Synthesis of Piperidine and Pyrrolidine Natural Alkaloids with Ring-Closing Metathesis as a Key Step. Eur. J. Org. Chem. 2003, 2003, 36933712 .

(4) (a) Trost, B. M. The Atom Economy-a Search for Synthetic Efficiency. Science 1991, 254, 1471-1477. (b) Trost, B. M. Atom Economy-A Challenge for Organic Synthesis: Homogeneous Catalysis Leads the Way. Angew. Chem. Int. Ed. Engl. 1995, 34, 259-281.

(5) For an excellent review covering enantioselective approaches, see: Nebe, M. M.; Opatz, T. Synthesis of Piperidines and Dehydropiperidines: Construction of the Six-Membered Ring. In Advances in Heterocyclic Chemistry, Vol 122; Scriven, E. F. V., Ramsden, C. A., Eds.; Academic Press: 2017; Vol. 122, pp 191-244.

(6) For the synthesis of piperidines with $\alpha$-quaternary stereocenters, see: (a) Beng, T. K.; Fox, N.; Bassler, D. P.; Alwali, A.; Sincavage, K.; Silaire, A. W. V. Trapping of Carbolithiation-Derived Tertiary Benzylic $\alpha$-Lithio Piperidines with Carbon Electrophiles: Controlling the Formation of $\alpha$-Amino Quaternary and Vicinal Stereocenters. Org. Biol. Chem. 2015, 13, 8647-8651. (b) Duttwyler, S.; Chen, S.; Lu, C.; Mercado, B. Q.; Bergman, R. G.; Ellman, J. A. Regio- and Stereoselective 1,2-Dihydropyridine Alkylation/Addition Sequence for the Synthesis of Piperidines with Quaternary Centers. Angew. Chem. Int. Ed. 2014, 53, 3877-3880. (c) Behenna, D. C.; Liu, Y.; Yurino, T.; Kim, J.; White, D. E.; Virgil, S. C.; Stoltz, B. M. Enantioselective Construction of Quaternary $\mathrm{N}$-Heterocycles by Palladium-Catalysed Decarboxylative Allylic Alkylation of Lactams. Nat. Chem. 2011, 4, 130-133.

(7) The piperidine ring is found in diversely substituted piperidine alkaloids, in bicyclic indolizidine, perhydroquinoline, and quinolizidine alkaloids, as well as in many of the most complex polycyclic alkaloids. See for instance: (a) Escolano, C.; Amat, M.; Bosch, J. Chiral Oxazolopiperidone Lactams: Versatile Intermediates for the Enantioselective Synthesis of Piperidine-Containing Natural Products. Chem. Eur. J. 2006, 12, 8198-8207. (b) See also references $2 \mathrm{a}, 3$ and 5.

(8) (a) Lounasmaa, M.; Tamminen, T. The Tropane Alkaloids. In Alkaloids: Chemistry and Pharmacology; Academic Press: New York, 1993, pp 1-114. (b) Grynkiewicz, G.; Gadzikowska, M. Tropane Alkaloids as Medicinally Useful Natural Products and their Synthetic Derivatives as New Drugs. Pharmacol. Rep. 2008, 60, 439-463. (c) Kukula-Koch, W. A.; Widelski, J. Alkaloids. In Pharmacognosy; Badal, S., Delgoda, R., Eds.; Academic Press: Boston, 2017; pp 163-198.

(9) For a review, see: (a) Pollini, G. P.; Benetti, S.; De Risi, C.; Zanirato, V. Synthetic Approaches to Enantiomerically Pure 8-Azabicyclo[3.2.1] octane Derivatives. Chem. Rev. 2006, 106, 2434-2454. For more recent examples, see: (b) Xu, J. H.; Zheng, S. C.; Zhang, J. W.; Liu, X. Y.; Tan, B. Construction of Tropane Derivatives by the Organocatalytic Asymmetric Dearomatization of Isoquinolines. Angew. Chem. Int. Ed. 2016, 55, 11834-11839. (c) Narayan, R.; Bauer, J. O.; Strohmann, C.; Antonchick, A. P.; Waldmann, H. Catalytic Enantioselective Synthesis of Functionalized Tropanes Reveals Novel Inhibitors of Hedgehog Signaling. Angew. Chem. Int. Ed. 2013, 52, 12892-12896. (d) Yu, Y.; Yang, X. F.; Xu, C. F.; Ding, C. H.; Hou, X. L. Desymmetrization of Bicyclo[3.n.1]-3-one Derivatives by Palladium-Catalyzed Asymmetric Allylic Alkylation. Org. Lett. 2013, 15, 3880-3883. (e) Reddy, R. P.; Davies, H. M. L. Asymmetric Synthesis of Tropanes by Rhodium-Catalyzed [4+3] Cycloaddition. J. Am. Chem. Soc. 2007, 129, 10312-10313.

(10) (a) Harada, S.; Kono, M.; Nozaki, T.; Menjo, Y.; Nemoto, T.; Hamada, Y. General Approach to Nitrogen-Bridged Bicyclic Frameworks by Rh-Catalyzed Formal Carbenoid Insertion into an Amide $\mathrm{C}-\mathrm{N}$ Bond. J. Org. Chem. 2015, 80, 10317-10333. (b) Neipp, C. E.; Martin, S. F. Synthesis of Bridged Azabicyclic Structures via Ring-Closing Olefin Metathesis. J. Org. Chem. 2003, 68, 8867-8878.

(11) (a) Alonso, I.; Trillo, B.; López, F.; Montserrat, S.; Ujaque, G.; Castedo, L.; Lledós, A.; Mascareñas, J. L. Gold-Catalyzed [4C + 2C] Cycloadditions of Allenedienes, Including an Enantioselective Version with New Phosphoramidite-Based Catalysts: Mechanistic Aspects of the Divergence between $[4 \mathrm{C}+3 \mathrm{C}]$ and $[4 \mathrm{C}+2 \mathrm{C}]$ Pathways. J. Am. Chem. Soc. 2009, 131, 13020-13030. (b) Trillo, B.; López, F.; Montserrat, S.; Ujaque, G.; Castedo, L.; Lledós, A.; Mascareñas, J. L. Gold-
Catalyzed [4C $+3 \mathrm{C}]$ Intramolecular Cycloaddition of Allenedienes: Synthetic Potential and Mechanistic Implications. Chem. Eur. J. 2009 15, 3336-3339. (c) Alonso, I.; Faustino, H.; López, F.; Mascareñas, J. L. Enantioselective Gold(I)-Catalyzed Intramolecular $(4+3)$ Cycloadditions of Allenedienes. Angew. Chem. Int. Ed. 2011, 50, 11496-11500. (d) Faustino, H.; Bernal, P.; Castedo, L.; López, F.; Mascareñas, J. L. Gold(I)-Catalyzed Intermolecular [2 + 2] Cycloadditions between Allenamides and Alkenes. Adv. Synth. Catal. 2012, 354, 1658-1664. (e) Francos, J.; Grande-Carmona, F.; Faustino, H.; Iglesias-Sigüenza, J.; Díez, E.; Alonso, I.; Fernández, R.; Lassaletta, J. M.; López, F.; Mascareñas, J. L. Axially Chiral Triazoloisoquinolin-3-ylidene Ligands in Gold(I)-Catalyzed Asymmetric Intermolecular $(4+2)$ Cycloaddition of Allenamides and Dienes. J. Am. Chem. Soc. 2012, 134, 14322 14325. (f) Fernández-Casado, J.; Nelson, R.; Mascareñas, J. L.; López, F. Synergistic Gold and Enamine Catalysis: Intermolecular $\alpha$-Alkylation of Aldehydes with Allenamides. Chem. Commun. 2016, 52, 29092912.

(12) Faustino, H.; Alonso, I.; Mascareñas, J. L.; López, F. Gold(I)-Catalyzed Cascade Cycloadditions between Allenamides and CarbonylTethered Alkenes: An Enantioselective Approach to Oxa-Bridged Medium-Sized Carbocycles. Angew. Chem. Int. Ed. 2013, 52, 6526-6530.

(13) (a) Faustino, H.; Varela, I.; Mascareñas, J. L.; López, F. Gold(I)-Catalyzed $[2+2+2]$ Cycloaddition of Allenamides, Alkenes and Aldehydes: a Straightforward Approach to Tetrahydropyrans. Chem. Sci. 2015, 6, 2903-2908. (b) Varela, I.; Faustino, H.; Díez, E.; IglesiasSigüenza, J.; Grande-Carmona, F.; Fernández, R.; Lassaletta, J. M.; Mascareñas, J. L.; López, F. Gold(I)-Catalyzed Enantioselective [2 + 2 + 2] Cycloadditions: An Expedient Entry to Enantioenriched Tetrahydropyran Scaffolds. ACS Catal. 2017, 7, 2397-2402.

(14) (a) Montserrat, S.; Faustino, H.; Lledós, A.; Mascareñas, J. L.; López, F.; Ujaque, G. Mechanistic Intricacies of Gold-Catalyzed Intermolecular Cycloadditions between Allenamides and Dienes. Chem. Eur. J. 2013, 19, 15248-15260. (b) Ocello, R.; De Nisi, A.; Jia, M.; Yang, Q.Q.; Monari, M.; Giacinto, P.; Bottoni, A.; Miscione, G. P.; Bandini, M Gold(I)-Catalyzed Dearomative [2+2]-Cycloaddition of Indoles with Activated Allenes: A Combined Experimental-Computational Study. Chem. Eur. J. 2015, 21, 18445-18453.

(15) (a) Garayalde, D.; Nevado, C. Gold-Containing and Gold-Generated $1, n$-Dipoles as Useful Platforms toward Cycloadditions and Cyclizations. ACS Catal. 2012, 2, 1462-1479. (b) Li, Y.; Li, W.; Zhang, J. Gold-Catalyzed Enantioselective Annulations. Chem. Eur. J. 2017, 23, 467-512. (c) Manoni, E.; Bandini, M. N-Allenyl Amides and O-Allenyl Ethers in Enantioselective Catalysis. Eur. J. Org. Chem. 2016, 2016, 3135-3142. (d) Harris, R. J.; Widenhoefer, R. A. Gold Carbenes, GoldStabilized Carbocations, and Cationic Intermediates Relevant to GoldCatalysed Enyne Cycloaddition. Chem. Soc. Rev. 2016, 45, 4533-4551. (e) Muratore, M. E.; Homs, A.; Obradors, C.; Echavarren, A. M. Meeting the Challenge of Intermolecular Gold(I)-Catalyzed Cycloadditions of Alkynes and Allenes. Chem. Asian. J. 2014, 9, 3066-3082. (f) López, F.; Mascareñas, J. L. Gold(I)-Catalyzed Enantioselective Cycloaddition Reactions. Beilstein J. Org. Chem. 2013, 9, 2250-2264. (g) López, F.; Mascareñas, J. L. Recent Developments in Gold-Catalyzed Cycloaddition Reactions. Beilstein J. Org. Chem. 2011, 7, 1075-1094. (h) Mascareñas, J. L.; López, F., Synthesis of Oxygenated Heterocyclic Compounds via Gold-Catalyzed Functionalization of $\pi$-Systems. In Au-Catalyzed Synthesis and Functionalization of Heterocycles, Bandini, M., Ed.; Springer International Publishing, 2016; pp 1-52.

(16) (a) Young, P. C.; Green, S. L. J.; Rosair, G. M.; Lee, A.-L. Deactivation of Gold(I) Catalysts in the Presence of Thiols and Amines - Characterisation and Catalysis. Dalton Trans. 2013, 42, 9645-9653. (b) Wang, Z.; Ying, A.; Fan, Z.; Hervieu, C.; Zhang, L. Tertiary Amino Group in Cationic Gold Catalyst: Tethered Frustrated Lewis Pairs That Enable Ligand-Controlled Regiodivergent and Stereoselective Isomerizations of Propargylic Esters. ACS Catal. 2017, 7, 3676-3680.

(17) For examples of imine-phosphine gold(I) complexes, see: (a) Schneider, W.; Bauer, A.; Schmidbaur, H. Synthesis, Isomerism and Supramolecular Chemistry of Diphenylmethanimine Complexes of the Coinage Metals. J. Chem. Soc., Dalton Trans. 1997, 415-420. (b) Schneider, W.; Bauer, A.; Schier, A.; Schmidbaur, H. Tetramethylguanidine and Benzophenoneimine as Ligands in Gold Chemistry. Chem. Ber. 1997, 130, 1417-1422.

(18) For examples of tertiary amine-phosphine gold(I) complexes, see: (a) Grohmann, A.; Riede, J. Schmidbaur, H. Z. Naturforsch, 1992, 47b, 1255-1260. (b) Vicente, J.; Chicote, M.-T.; Guerrero, R.; Jones, P. G. 
Synthesis of Complexes $\left[\mathrm{Au}\left(\mathrm{PPh}_{3}\right) \mathrm{L}\right]^{+}(\mathrm{L}=$ Primary, Secondary or Tertiary Amine). Crystal structure of $\left[\mathrm{Au}\left(\mathrm{PPh}_{3}\right)\left(\mathrm{NMe}_{3}\right)\right]\left[\mathrm{ClO}_{4}\right] \cdot \mathrm{CH}_{2} \mathrm{Cl}_{2}$.J. Chem. Soc., Dalton Trans. 1995, 1251-1254.

(19) For instance, see: (a) Lavallo, V.; Frey, G. D.; Donnadieu, B.; Soleilhavoup, M.; Bertrand, G. Homogeneous Catalytic Hydroamination of Alkynes and Allenes with Ammonia. Angew. Chem. Int. Ed. 2008, 47, 5224-5228. (b) Hesp, K. D.; Stradiotto, M. Stereo- and Regioselective Gold-Catalyzed Hydroamination of Internal Alkynes with Dialkylamines. J. Am. Chem. Soc. 2010, 132, 18026-18029. (c) Zhdanko, A.; Maier, M. E. Mechanistic Study of Gold(I)-Catalyzed Hydroamination of Alkynes: Outer or Inner Sphere Mechanism? Angew. Chem. Int. Ed. 2014, 53, 7760-7764. See also reference $11 \mathrm{f}$.

(20) For representative cases, see: (a) Shapiro, N. D.; Toste, F. D. Synthesis of Azepines by a Gold-Catalyzed Intermolecular [4 + 3]-Annulation. $J$. Am. Chem. Soc. 2008, 130, 9244-9245. (b) Fernández-García, J. M.; Fernández-Rodríguez, M. Á.; Aguilar, E. Catalytic Intermolecular Hetero-Dehydro-Diels-Alder Cycloadditions: Regio- and Diasteroselective Synthesis of 5,6-Dihydropyridin-2-ones. Org. Lett. 2011, 13, 5172-5175. (c) Bai, Y.; Tao, W.; Ren, J.; Wang, Z. Lewis Acid Catalyzed Intramolecular [4 +2] and [3+2] Cross-Cycloaddition of Alkynylcyclopropane Ketones with Carbonyl Compounds and Imines. Angew. Chem. Int. Ed. 2012, 51, 4112-4116. (d) Iqbal, N.; Fiksdahl, A. Gold(I)-Catalyzed Benz[c]azepin-4-ol Synthesis by Intermolecular [5 + 2] Cycloaddition. J. Org. Chem. 2013, 78, 7885-7895. (e) Wang, L.; Xie, X.; Liu, Y. Gold-Catalyzed Oxidative Rearrangement Involving 1,2-Acyl Migration: Efficient Synthesis of Functionalized Dihydro- $\gamma$ Carbolines from $\alpha$-(2-Indolyl) Propargylic Alcohols and Imines. Angew. Chem. Int. Ed. 2013, 52, 13302-13306. (f) Xin, Z.; Kramer, S.; Overgaard, J.; Skrydstrup, T. Access to 1,2-Dihydroisoquinolines through Gold-Catalyzed Formal [4 + 2] Cycloaddition. Chem. Eur. J. 2014, 20, 7926-7930. (g) Peng, S.; Cao, S.; Sun, J. Gold-Catalyzed Regiodivergent $[2+2+2]$-Cycloadditions of Allenes with Triazines. Org. Lett. 2017, 19, 524-527. (h) Peng, S.; Ji, D.; Sun, J. Gold-catalyzed $[2+2+2+2]$-Annulation of 1,3,5-Hexahydro-1,3,5-Triazines with Alkoxyallenes. Chem. Commun. 2017, 53, 12770-12773. (i) Pawar, S. K.; Yang, M. C.; Su, M. D.; Liu, R. S., Gold-Catalyzed Oxidative $[2+2+1]$ Annulations of Aryldiazo Nitriles with Imines To Yield Polyarylated Imidazolium Salts. Angew. Chem. Int. Ed. 2017, 56, 5035-5039.

(21) To the best of our knowledge, there is only a single report on aza-Prins cyclizations invoving vinyl-gold species, see: (a) Kim, C.; Bae, H. J.; Lee, J. H.; Jeong, W.; Kim, H.; Sampath, V.; Rhee, Y. H. Formal Alkyne Aza-Prins Cyclization: Gold(I)-Catalyzed Cycloisomerization of Mixed $\mathrm{N}, \mathrm{O}$-Acetals Generated from Homopropargylic Amines to Highly Substituted Piperidines. J. Am. Chem. Soc. 2009, 131, 1466014661. On the contrary, oxo-Prins cyclizations on gold catalysis are significantly developed, see: (b) Jimenez-Nuñez, E.; Claverie, C. K.; Nieto-Oberhuber, C.; Echavarren, A. M. Prins Cyclizations in Au-Catalyzed Reactions of Enynes. Angew. Chem. Int. Ed. 2006, 45, 54525455. (c) Bae, H. J.; Jeong, W.; Lee, J. H.; Rhee, Y. H. Gold(I)-Catalyzed Access to Tetrahydropyran-4-ones from 4-(Alkoxyalkyl)oxy-1butynes: Formal Catalytic Petasis-Ferrier Rearrangement. Chem. Eur. J. 2011, 17, 1433-1436. (d) Calleja, P.; Muratore, M. E.; Jiménez, T.; Echavarren, A. M. Diastereoselective Gold(I)-Catalyzed [2+2 + 2] Cycloaddition of Oxo-1,5-enynes. Synthesis 2016, 48, 3183-3198.

(22) For references covering the formation of this type of bimolecular products, see: (a) Kimber, M. C. A Facile and Mild Synthesis of Enamides Using a Gold-Catalyzed Nucleophilic Addition to Allenamides. Org. Lett. 2010, 12, 1128-1131. (b) Faustino, H.; Bernal, P.; Castedo, L.; López, F.; Mascareñas, J. L. Gold(I)-Catalyzed Intermolecular [2 + 2] Cycloadditions between Allenamides and Alkenes. Adv. Synth. Catal. 2012, 354, 1658-1664. (c) Hernández-Díaz, C.; Rubio, E.; González, J. M. Gold-Catalyzed Allenamide [2+2+2]-Cyclotrimerization. Eur. J. Org. Chem. 2016, 2016, 265-269. (d) Li, X.-X.; Zhu, L.-L.; Zhou W.; Chen, Z. Formal Intermolecular [2+2] Cycloaddition Reaction of Alleneamides with Alkenes via Gold Catalysis. Org. Lett. 2012, 14, 436439. (e) Jia, M.; Monari, M.; Yang, Q.-Q.; Bandini, M., Enantioselective Gold Catalyzed Dearomative [2 + 2]-Cycloaddition between Indoles and Allenamides. Chem. Commun. 2015, 51, 2320-2323. (f) Wang, Y.; Zhang, P.; Liu, Y.; Xia, F.; Zhang, J. Enantioselective GoldCatalyzed Intermolecular [2+2] versus [4+2]-Cycloadditions of 3Styrylindoles with $N$-Allenamides: Observation of Interesting Substituent Effects. Chem. Sci. 2015, 6, 5564-5570. For a review on the chemistry of allenamides, see: (g) Lu, T.; Lu, Z.; Ma, Z.-X.; Zhang, Y.;
Hsung, R. P. Allenamides: A Powerful and Versatile Building Block in Organic Synthesis. Chem. Rev. 2013, 113, 4862-4904.

(23) See the Supporting Information for further details.

(24) Structure of 9aa is preliminary proposed on the basis of the ${ }^{1} \mathrm{H}-\mathrm{NMR}$ spectra of the crude reaction mixture, and based on its analogy with previously reported related hydrofunctionalization products. See refs. $11 \mathrm{~d}$ and 22a.

(25) (a) Lewis Basicity and Affinity Scales; Laurence, C., Gal, J.-F. Eds.; John Wiley \& Sons; 2010. West Sussex, U.K. (b) Kalia, J.; Raines, R. T. Hydrolytic Stability of Hydrazones and Oximes. Angew. Chem. Int. Ed. 2008, 47, 7523-7526. (c) Ciula, J. C.; Streitwieser, A. Carbon acidity. 79. Acidity of Enolate Equivalent Compounds: Oxime Ethers. $J$. Org. Chem. 1991, 56, 1989-1993.

(26) (a) Mirjafary, Z.; Abdoli, M.; Saeidian, H.; Kakanejadifard, A.; Farnia, S. M. F. Review of the Synthesis of Acyclic and Cyclic Oxime Ethers. RSC Advances 2016, 6, 17740-17758. (b) Buehler, E. Alkylation of syn- and anti-Benzaldoximes. J. Org. Chem. 1967, 32, 261-264. (c) Eshghi, H.; Gordi, Z. $\mathrm{P}_{2} \mathrm{O}_{5} / \mathrm{SiO}_{2}$ as an Efficient Reagent for the Preparation of Z-Aldoximes under Solvent-free Conditions. Phosphorus, Sulfur, Silicon Relat. Elem. 2005, 180, 1553-1557.

(27) (a) Mirjafary, Z.; Abdoli, M.; Saeidian, H.; Boroon, S.; Kakanejadifard, A. Oxime Ethers as Versatile Precursors in Organic Synthesis: A Review. RSC Advances 2015, 5, 79361-79384. (b) Abele, E.; Lukevics, E. Synthesis of Heterocycles from Oximes. In The Chemistry of Hydroxylamines, Oximes and Hydrozamic Acids, Rappoport, Z., Liebman, J. F. Eds.; 2009, John Wiley \& Sons, pp. 233-302.

(28) Bolotin, D. S.; Bokach, N. A.; Demakova, M. Y.; Kukushkin, V. Y. Metal-Involving Synthesis and Reactions of Oximes. Chem. Rev. 2017, 117, 13039-13122.

(29) (a) Ueda, M.; Sato, A.; Ikeda, Y.; Miyoshi, T.; Naito, T.; Miyata, O. Direct Synthesis of Trisubstituted Isoxazoles through Gold-Catalyzed Domino Reaction of Alkynyl Oxime Ethers. Org. Lett. 2010, 12, 25942597. (b) Ngwerume, S.; Camp, J. E. Gold-Catalysed Rearrangement of $O$-Vinyl Oximes for the Synthesis of Highly Substituted Pyrroles. Chem. Commun. 2011, 47, 1857-1859. (c) Zhang, Y.; Zhang, J. Gold(I)-Catalyzed Regio- and Stereoselective 1,3-Dipolar Cycloaddition Reactions of 1-(1-Alkynyl)cyclopropyl Oximes with Nitrones: A Modular Entry to Highly Substituted Pyrrolo [3,4-d][1,2]Oxazepines. Adv. Synth. Catal. 2012, 354, 2556-2560. (d) Jeong, Y.; Kim, B.-I.; Lee, J. K.; Ryu, J.-S. Direct Synthesis of 4-Fluoroisoxazoles through Gold-Catalyzed Cascade Cyclization-Fluorination of 2-Alkynone $O$ Methyl Oximes. J. Org. Chem. 2014, 79, 6444-6455. (e) Sugita, S.; Takeda, N.; Tohnai, N.; Miyata, M.; Miyata, O.; Ueda, M. Gold-Catalyzed [3 + 2]/ Retro-[3 + 2] / [3 + 2] Cycloaddition Cascade Reaction of $N$-Alkoxyazomethine Ylides. Angew. Chem. Int. Ed. 2017, 56, 24692472.

(30) (a) Jackson, S. K.; Karadeolian, A.; Driega, A. B.; Kerr, M. A. Stereodivergent Methodology for the Synthesis of Complex Pyrrolidines. $J$. Am. Chem. Soc. 2008, 130, 4196-4201. (b) Deng, L.; Xu, T.; Li, H.; Dong, G. Enantioselective Rh-Catalyzed Carboacylation of $\mathrm{C}=\mathrm{N}$ Bonds via C-C Activation of Benzocyclobutenones. J. Am. Chem. Soc. 2016, 138, 369-374. (c) Lin, T.-Y.; Wu, H.-H.; Feng, J.-J.; Zhang, J. Chirality Transfer in Rhodium(I)-Catalyzed [3 + 2]-Cycloaddition of Vinyl Aziridines and Oxime Ethers: Atom-Economical Synthesis of Chiral Imidazolidines. Org. Lett. 2018, 20, 3587-3590.

(31) Conversely, $\mathrm{O}$-unsubstituted oximes $(\mathrm{C}=\mathrm{N}-\mathrm{OH})$ have been frequently used in cycloaddition reactions, mostly as precursors of nitrile oxides and nitrones. See: Rai, K. M. L.: Heterocycles via Oxime Cycloadditions. In Synthesis of Heterocycles Via Cycloadditions; Hassner, A., Ed.; Topics in Heterocyclic Chemistry, 2008; Vol. 13; pp 1-69.

(32) In few cases, the parent oxime partner employed in the cycloaddition consisted of a $E$ / $Z$ mixture (from $6: 1$ to $15: 1$ ). Only in these cases, small amounts of the trans adducts of type 11' were observed in the crude mixture (11/ 11' ratios $>15: 1)$. The isomeric ratio of the products $(\mathbf{1 1} / \mathbf{1 1}$ ') was consistently higher than that of the parent oximes 10, due to the higher reactivity of the $E$-isomers. See the Supp. Info. for each case.

(33) The 8-azabicyclo[3.2.1]octane derivative 15aa was isolated as a $2.6: 1$ mixture of $\mathrm{N}$-invertomers (equatorial and axial $\mathrm{N}-\mathrm{OMe}$ disposition). This was confirmed by variable temperature NMR and derivatization experiments (see the Supporting Information). For selected precedents on this isomerism in tropane scaffolds, see: (a) Kashman, Y.; Cherkez, S. The Synthesis of Heterocyclic Systems from Cyclohepta-2,6dienone. Synthesis 1974; 1974, 885-887. (b) Cherkez, S.; Yellin, H.; 
Kashman, Y.; Yaavetz, B.; Sokolovsky, M. Structure-Activity Relationship in a New Series of Atropine Analogs. II. Effect of an Asymmetric N-Substituent on Anti-Muscarinic Activity. Mol. Pharmacol. 1978, 14, 781-786. (c) Lamanec, T. R.; Bender, D. R.; DeMarco, A. M.; Karady, S.; Reamer, R. A.; Weinstock, L. M. $\alpha$-Effect Nucleophiles: A Novel and Convenient Method for the Synthesis of Dibenzo[a,d]Cycloheptenimines. J. Org. Chem. 1988, 53, 1768-1774. (d) Lazny, R.; Ratkiewicz, A.; Nodzewska, A.; Wynimko, A.; Siergiejczyk, L. Determination of the $N$-Methyl Stereochemistry in Tropane and Granatane Derivatives in Solution: a Computational and NMR Spectroscopic Study. Tetrahedron 2012, 68, 6158-6163.

(34) For related transformations, see: Reich, H. J.; Wollowitz, S, Preparation of $\alpha, \beta$-Unsaturated Carbonyl Compounds and Nitriles by Selenoxide Elimination. Org. React. (Hoboken, NJ, U. S.) 1993, 44, pp 1-296.

(35) Generally, when cycloadditions were carried out with $E / Z$ mixtures of oxime ethers of type 10, mixtures of the corresponding piperidines $\mathbf{1 1}$ and 11' were obtained, both of them with the same er values (see Table S7). ${ }^{23}$

(36) See also: González, A. Z.; Benitez, D.; Tkatchouk, E.; Goddard, W. A., 3rd; Toste, F. D., Phosphoramidite Gold(I)-Catalyzed Diastereo- and Enantioselective Synthesis of 3,4-Substituted Pyrrolidines. J. Am. Chem. Soc. 2011, 133, 5500-5507.

(37) As a representative case, whereas the $[2+2+2]$ adduct 11 bg is obtained with $85: 15$ er $(59 \%$ yield), its corresponding [2+2] side product 12bg (15\% yield) is isolated with an er of 93:7 (Table 5). See Table S8 for additional cases.

(38) Suárez-Pantiga, S.; Hernández-Diaz, C.; Rubio, E.; González, J. M., Intermolecular [2 +2] Reaction of $N$-Allenylsulfonamides with Vinylarenes: Enantioselective Gold(I)-Catalyzed Synthesis of Cyclobutane Derivatives. Angew. Chem. Int. Ed. 2012, 51, 11552-11555.

(39) Adduct 15gb (54\% yield and $85: 15$ er) was obtained from $N$-pyrenyl tosyl allenamide $1 \mathrm{~g}$ and the alkenyl oxime $E-\mathbf{1 4 b} .^{23}$

(40) In consonance with these results, when a different $E / Z$ mixture of 10a was used (e.g. $E / Z=3.5: 1$ ), the observed ratio between 11aa and 11aa' (11aa / 11aa' $=5.8: 1)$ again reflected a 1.6 fold isomeric enrichment in favor of the cis isomer 11aa.

(41) The aza-Prins cyclization is expected to be faster with electron deficient groups at the $C$-oxime substituent.

(42) (a) In consonance with these results, $O$-alkenyl oximes of type $\mathbf{1 0}$ with longer tethers between the alkene and the oxime ether only provided the competitive [2 + 2] side-product (see the Supporting Information, Scheme S2). (b) Likewise, fully intermolecular reactions between allenamide 1a, $\alpha$-methyl styrene $\mathbf{2 a}$ and different types of aldehyde oxime ethers only provided the bimolecular [2+2] cycloadduct 5aa. Further studies to identify the appropriate type of oxime that could participate in this intermolecular $[2+2+2]$ transformation are underway. 


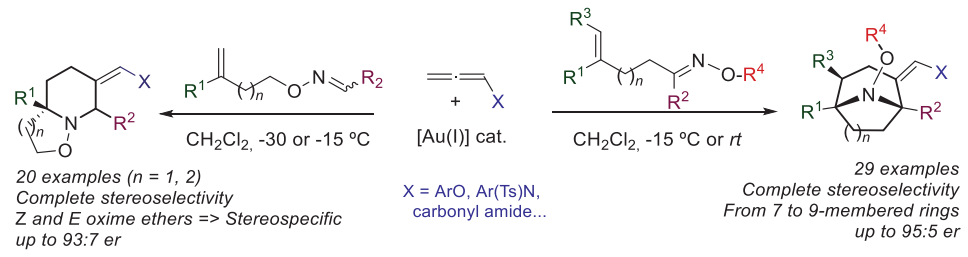

